\title{
Tumor therapy in mice via antigen targeting to a novel, DC-restricted C-type lectin
}

\author{
David Sancho,' Diego Mourão-Sá, ${ }^{1}$ Olivier P. Joffre, ${ }^{1}$ Oliver Schulz,, ${ }^{1}$ Neil C. Rogers, ${ }^{1}$ \\ Daniel J. Pennington, ${ }^{2}$ James R. Carlyle, ${ }^{3}$ and Caetano Reis e Sousa ${ }^{1}$
}

\begin{abstract}
1Immunobiology Laboratory, Cancer Research UK, London Research Institute, London, United Kingdom. 2Institute of Cell and Molecular Science, Barts and the London School of Medicine and Dentistry, Queen Mary, University of London, London, United Kingdom. ${ }^{3}$ Department of Immunology, University of Toronto, and Sunnybrook Research Institute, Toronto, Ontario, Canada.
\end{abstract}

\begin{abstract}
The mouse CD8 $\alpha^{+}$DC subset excels at cross-presentation of antigen, which can elicit robust CTL responses. A receptor allowing specific antigen targeting to this subset and its equivalent in humans would therefore be useful for the induction of antitumor CTLs. Here, we have characterized a C-type lectin of the NK cell receptor group that we named DC, NK lectin group receptor-1 (DNGR-1). DNGR-1 was found to be expressed in mice at high levels by $\mathrm{CD8}^{+}$DCs and at low levels by plasmacytoid DCs but not by other hematopoietic cells. Human DNGR-1 was also restricted in expression to a small subset of blood DCs that bear similarities to mouse CD8 $\alpha^{+}$ DCs. The selective expression pattern and observed endocytic activity of DNGR-1 suggested that it could be used for antigen targeting to DCs. Consistent with this notion, antigen epitopes covalently coupled to an antibody specific for mouse DNGR-1 were selectively cross-presented by CD8 $\alpha^{+}$DCs in vivo and, when given with adjuvants, induced potent CTL responses. When the antigens corresponded to tumor-expressed peptides, treatment with the antibody conjugate and adjuvant could prevent development or mediate eradication of $B 16$ melanoma lung pseudometastases. We conclude that DNGR-1 is a novel, highly specific marker of mouse and human DC subsets that can be exploited for CTL cross-priming and tumor therapy.
\end{abstract}

\section{Introduction}

DCs are versatile controllers of $\mathrm{T}$ lymphocyte responses, contributing to the maintenance of self tolerance and to the induction of adaptive immunity (1). It is becoming increasingly apparent that such functional versatility involves the specialized activities of different DC subtypes (2). Both mice and humans possess at least 3 broad groups of DCs, encompassing plasmacytoid DCs (pDCs), blood-derived conventional DCs (cDCs), and tissue-derived cDCs (2). These groups can be subdivided into distinct subsets with different markers, diverse functions, distinct ontogeny, and differential turnover in vivo (2). The best-studied mouse DC subsets are the blood-derived $\mathrm{CD} 8 \alpha^{+} \mathrm{cDCs}, \mathrm{CD} 4^{+} \mathrm{cDCs}$, and $\mathrm{CD} 4-\mathrm{CD} 8 \alpha-$ (double-negative $[\mathrm{DN}]) \mathrm{cDCs}$ found in lymphoid organs $(3,4)$. Mouse CD $8 \alpha^{+}$DCs excel in MHC class I cross-presentation of cell-associated foreign and self antigens (5-8), partly due to their ability to capture material from dying cells $(9,10)$ and to efficiently process exogenous antigen for MHC class I cross-presentation (11-13). These 2 properties of CD $8 \alpha^{+}$DCs may also underlie their ability to serve as efficient APCs for CTL priming in several infection models (14-19). In contrast, CD8 $\alpha^{-}$DCs, encompassing $\mathrm{CD}^{+}$DCs and DN DCs (20), are relatively better at presenting exogenous antigens on MHC class II and directing $\mathrm{CD}^{+} \mathrm{T}$ cell responses (11-13).

The superior ability of DCs to regulate adaptive immunity suggests that significant clinical potential could be gained from tar-

Nonstandard abbreviations used: BCDA-2, blood DC antigen 2; BMDC, BMderived DC; cDC, conventional DC; Clec9a, C-type lectin 9a; CTLD, C-type lectin-like domain; DN, double negative; DNGR-1, DC, NK lectin group receptor-1; gp100, melanocyte lineage-specific antigen glycoprotein 100; MFI, median fluorescence intensity; pDC, plasmacytoid DC; S1, SIINFEKLC-eahx-biotin; S2, SIINFEKLTEWTSSNV-

MEERC-eahx-biotin; TRP-1, tyrosinase-related protein 1.

Conflict of interest: The authors have declared that no conflict of interest exists. Citation for this article: J. Clin. Invest. 118:2098-2110 (2008). doi:10.1172/JCI34584. geting antigens to DCs in vivo $(21,22)$. One practical approach has been to administer antigens coupled to antibodies directed against DC surface receptors. When given together with an adjuvant, such antibody conjugates can elicit powerful Th1 and CTL responses, useful for immunotherapy of cancer or for boosting cellular immunity to infections (23-29). Conversely, in the absence of an adjuvant, antibody-mediated DC targeting can induce antigenspecific tolerance, helpful for limiting autoimmune reactions or responses to allografts and allergens $(23,24,30-32)$. Successful targeting depends on identifying suitable DC-expressed cell-surface receptors that mediate endocytosis of bound antibodies. This allows delivery of the latter to endosomal and/or cytosolic compartments where their associated antigens can be processed for MHC presentation. Possible receptors include ones shared by DCs and other cell types, such as the macrophage mannose receptor or the Fcy receptors, as well as others more restricted to DCs, such as DEC-205, DC-SIGN, langerin, asialoglycoprotein receptor, or blood DC antigen 2 (BDCA-2) (reviewed in refs. 21, 22, 33). Many of these receptors belong to the C-type lectin family and may have a physiological role in antigen capture, which renders them especially suitable for targeting $(34,35)$. Many mouse C-type lectins that are potentially useful for antigen targeting are preferentially expressed in CD8 $\alpha^{-}$DCs and include dectin-1, dectin-2, DCIR2, FIRE, and CIRE $(12,13,36,37)$. In contrast, $\mathrm{CD} 8 \alpha^{+} \mathrm{DCs}$ can be targeted by antibodies against DEC-205, a C-type lectin that delivers ligands to late endosomal/lysosomal compartments $(38,39)$. Antigen targeting to dectin-1 or DCIR2 in vivo favors $\mathrm{CD} 4^{+} \mathrm{T}$ cell responses, whereas targeting to DEC-205 is especially effective at inducing $\mathrm{CD}^{+} \mathrm{T}$ cell responses, in line with the aforementioned differences in antigen handling by $\mathrm{CD} 8 \alpha^{+}$and $\mathrm{CD} 8 \alpha^{-} \mathrm{DCs}(12$, 13). This suggests that antigen targeting to DEC-205 might be useful for inducing protective CTL-based immunity in diseases such as cancer, malaria, and HIV. Unfortunately, mouse DEC-205 
A

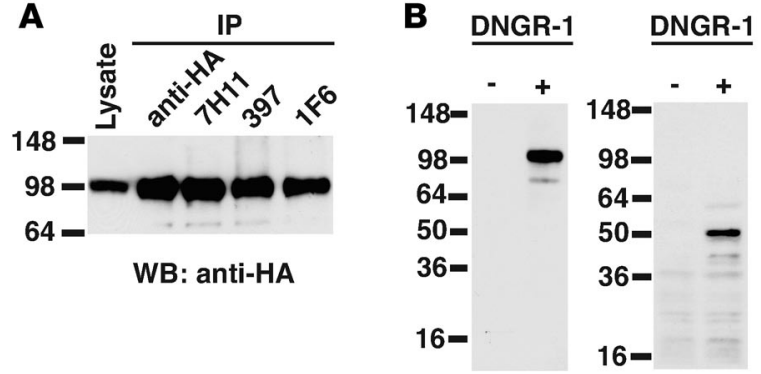

Figure 1

Biochemical characterization of mouse DNGR-1 protein. (A) Lysate from Phoenix cells stably transfected with a retroviral vector encoding HA-tagged mDNGR-1 was Western blotted (WB) with anti-HA before or after immunoprecipitation with anti-HA or the indicated anti-mDNGR-1 antibodies. (B) Western blot using anti-DNGR-1 mAb 397 to probe lysates of Phoenix cells expressing (+) or not expressing (-) DNGR-1 under reducing (right) and nonreducing (left) conditions.

is not only expressed in CD8 $\alpha^{+}$DCs but also in subsets of lymph node cDCs, Langerhans cells, interstitial DCs, thymic epithelial cells, and at lower levels, in B cells, macrophages, T cells, and granulocytes (38, 40-42). Human DEC-205 shows an even broader distribution (43). Therefore other receptors that might selectively allow targeting of mouse CD8 $\alpha^{+}$DCs in vivo or their equivalent in humans would be welcome additions to the repertoire of DC targets for inducing CTL-based immunity.

Here, we describe $\underline{\mathrm{D}}$, $\underline{\mathrm{NK}}$ lectin group receptor-1 (DNGR-1) as a previously uncharacterized C-type lectin that is selectively expressed in mouse CD8 $\alpha^{+} \mathrm{cDCs}$ and, at low levels, on pDCs but not in other cell types. We show that DNGR-1 acts as an endocytic receptor that can mediate internalization of bound antibody and can be targeted for antigen delivery in vivo to $C D 8 \alpha^{+}$DCs. This allows cross-presentation to $\mathrm{CD} 8^{+} \mathrm{T}$ cells and, together with an adjuvant, induces potent CTL responses that can cure mice of a transplantable tumor. Notably, we find that DNGR-1 is also selectively expressed in a small subset of human DCs. Thus, DNGR-1 constitutes a selective marker for human and mouse DC subsets and can be exploited for antigen delivery to these cells in vivo.

\section{Results}

Identification and characterization of DNGR-1. To identify markers for mouse DC subsets, we carried out representational difference analysis of freshly-isolated mouse spleen CD $11 \mathrm{c}^{+} \mathrm{CD} 8 \alpha^{+}$and CD1 $1 c^{+} \mathrm{CD} 8 \alpha^{-}$cells (O. Schulz, D.J. Pennington, and C. Reis e Sousa, unpublished observations). Sequences matching EST clone AW318446, corresponding to the mouse C-type lectin 9A (Clec9a) gene, were highly represented among $\mathrm{CD} 8 \alpha^{+} \mathrm{DC}-$ specific transcripts (data not shown). Genome annotation predicts the presence of CLEC9A genes in Mus musculus, Pan troglodytes, Homo sapiens, Canis lupus familiaris, and Macaca mulatta. A database search using part of the protein sequence of mouse CLEC9A further suggests the presence of CLEC9A genes in Rattus norvegicus and Bos taurus (44).

CLEC9A is predicted to be a type II transmembrane receptor of the C-type lectin family with a single extracellular C-type lectin-like domain (CTLD) (Supplemental Figures 1 and 2; supplemental material available online with this article; doi:10.1172/ JCI34584DS1). The CTLD contains 6 conserved cysteine residues likely to be involved in intrachain disulfide bond formation as well as other conserved features of CTLDs (45) but lacks the $\mathrm{Ca}^{2+}$-coordinating amino acid residues found in typical carbohydrate-recognition domains (Supplemental Figures 1 and 2). The CLEC9A CTLD is linked to a stalk region containing a conserved cysteine putatively involved in dimerization (see below). This is followed by a transmembrane region and a cytoplasmic domain with a highly conserved tyrosine (Supplemental Figures 1 and 2). The mouse gene contains 7 exons whereas the human contains 9 exons, 6 of which have been annotated as contributing to mRNA (Supplemental Figure 1). In mice, we have found transcripts for 3 isoforms of Clec9a (Supplemental Figure 3) that we have termed long isoform (exons 1-7), short isoform (lacking exon 4 but keeping the same reading frame), and very short isoform (exons 1-3 fused to exon 7 , encoding a protein that, if expressed, would share the transmembrane and intracellular domains with CLEC9A but would have a short and distinct extracellular domain). Published analysis suggests that the CLEC9A CTLD is closely related to that found in the killer cell lectin receptor I (KLR-I) (44). Our analysis shows that, despite having a high degree of similarity to KLR-I and other members of the KLR complex, CLEC9A is phylogenetically most closely related to CLEC7A, commonly known as dectin-1 (Supplemental Figure 4). Notably, both CLEC9A and dectin-1 as well as KLR-I belong to the NK cell receptor group of C-type lectins (group V). In line with this notion and in accordance with its DCrestricted expression pattern in mouse and human (see below), we have named the protein DNGR-1.

We cloned the mouse DNGR-1 cDNA from spleen CD8 $\alpha^{+}$DCs. Transfection studies using a $C$ terminus-tagged version of the receptor indicated that it could be expressed and transported to the cell surface in heterologous cells (data not shown). To study expression in more detail, we generated mAbs against DNGR-1 (see Methods). We selected 3 rat anti-mouse DNGR-1 mAbs named $1 \mathrm{~F} 6,397$, and 7H11 that specifically stained cells stably transfected with mDNGR-1 cDNA (Supplemental Figure 5) and recognize both the short and the long isoform, which differ only in a segment of the stalk region (data not shown). All 3 mAbs could be used to immunoprecipitate HA-tagged mDNGR-1 from transfected cells (Figure 1A). The apparent molecular weight (MW) of DNGR-1 was around $102 \mathrm{kDa}$ in nonreducing conditions and around $51 \mathrm{kDa}$ in reducing conditions (Figure $1 \mathrm{~B}$ ). This indicates that the molecule exists as a dimer, probably stabilized by a disulfide bond involving the conserved cysteine in the stalk region (Supplemental Figure 2), as commonly found in other NK receptor group V C-type lectins (45). Notably, the MW of the monomer was significantly higher than the $29.7 \mathrm{kDa}$ predicted from the sequence of the core protein, suggesting that the receptor is heavily glycosylated. Consistent with this possibility, mouse and human DNGR-1 have 1 putative $\mathrm{N}$-glycosylation site (Asn81) and 1 putative attachment site for glycosaminoglycans (Ser104 in mice and Ser106 in humans), both in the stalk region (Supplemental Figure 2).

Expression of DNGR-1 is restricted to $C D 8 \alpha^{+} D C$ s and $p D C$. We examined the pattern of expression of mDNGR-1 in mouse tissues. In spleen, the molecule was expressed by a subset of CD11 $\mathrm{c}^{+} \mathrm{DCs}$ but not by CD11 $c^{-}$cells, including B cells, T cells, NK cells, NKT cells, monocytes, macrophages, or granulocytes (Figure 2A and data not shown). Within the DC fraction, DNGR-1 was expressed at very high levels by $\mathrm{CD} 8 \alpha^{+} \mathrm{cDCs}$ but not by $\mathrm{CD} 4^{+}$or $\mathrm{DN} \mathrm{cDCs}$ (Figure $2 \mathrm{~A})$. In addition, the receptor was also expressed in $\mathrm{pDCs}$ but at a significantly lower level than in $\mathrm{CD} 8 \alpha^{+} \mathrm{cDCs}$ (median fluorescence intensity $[\mathrm{MFI}] \approx 60$ compared with $\approx 400$; isotype control 

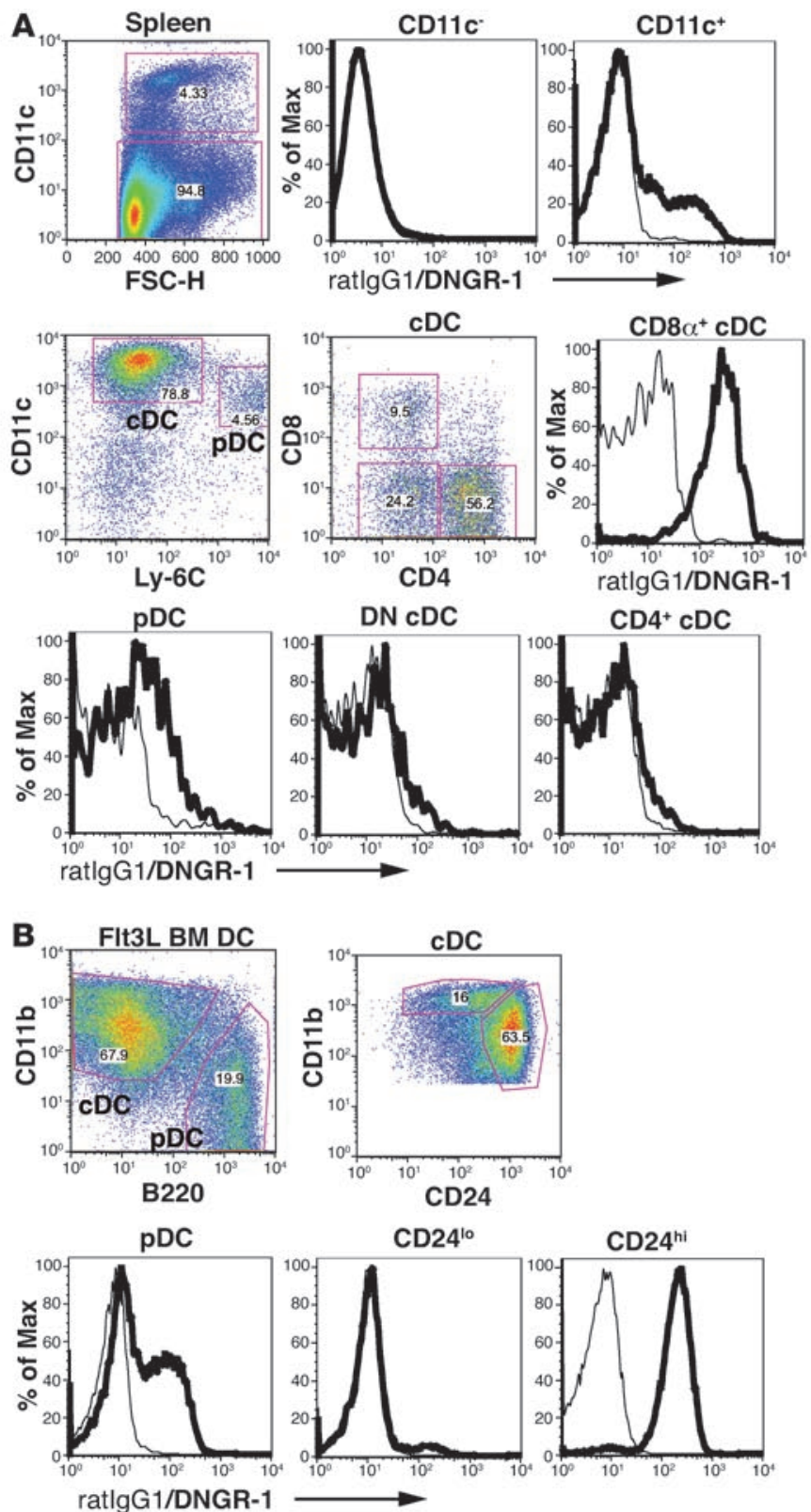

$\mathrm{MFI} \approx 8$ ). In addition, $\mathrm{CD} 8 \alpha^{+} \mathrm{DC}$ staining was unimodal, indicating uniform expression of DNGR-1 whereas the staining of pDCs was less clear and might represent expression by a subpopulation of the cells (Figure 2A and data not shown; see below). The pattern of DNGR-1 expression as assessed by antibody staining largely agreed with analysis of DNGR-1 mRNA expression in sorted DC subsets (Supplemental Figure 3).

Similar to spleen, expression of DNGR-1 in lymph nodes and in thymus was also restricted to $\mathrm{CD} 8 \alpha^{+} \mathrm{cDCs}$ and $\mathrm{pDCs}$, but expression levels in the former subset were always much higher than in the latter (Supplemental Figure 6 and data not shown). No staining was detectable on tissue-derived DCs such as interstitial DCs and (in s.c. lymph nodes) the putative descendants of skin dermal DCs and Langerhans cells (Supplemental Figure 6). Likewise, DNGR-1 was not expressed in skin epidermis or in other nonlymphoid tissues (data not shown).

\section{Figure 2}

Mouse DNGR-1 expression is restricted to CD8 $\alpha^{+}$DCs and pDCs. (A) Expression of DNGR-1 in mouse spleen. Splenocytes were stained with biotin anti-DNGR-1 7H11 (thick line) or biotin rat IgG1 (thin line; isotype-matched control) followed by streptavidin-PE and antibodies to CD11c, CD4, CD8 $\alpha$, and Ly6C. CD11 ${ }^{+}$and CD11 ${ }^{-}$cells (upper row) or different DC subsets (lower rows) were defined by electronic gating as shown on the dot plots. DNGR-1 expression is shown in the corresponding histograms. Numbers indicate percentage of events in gate. (B) Expression of DNGR-1 in Flt3L-BMDCs. Histograms show staining with anti-DNGR-1 (thick line) compared with isotype-matched control (thin line) in B220+ cells corresponding to pDCs, CD24 ${ }^{\text {hi }} \mathrm{CD} 11 \mathrm{~b}^{\text {lo }}$ cells corresponding to $C D 8 \alpha^{+} \mathrm{DCs}$, and $\mathrm{CD} 24^{\mathrm{l}} \mathrm{CD} 11 \mathrm{~b}^{\mathrm{hi}}$ cells corresponding to $C D 8 \alpha^{-}$DCs after gating as indicated. Numbers represent percentage of events in the indicated gate.

As a model for analysis of DNGR-1 function in vitro, we analyzed expression in mouse BM-derived DCs (BMDCs) generated by culture in GM-CSF or in Flt3L. DNGR-1 was not expressed by GM-CSF BMDCs (data not shown) but was highly expressed in the $\mathrm{CD} 11 \mathrm{~b}^{\text {lo }} \mathrm{CD} 24^{\text {hi }} \mathrm{B} 220^{-}$subset of Flt3L BMDCs (Figure $2 \mathrm{~B}$ ), which corresponds to the CD8 $\alpha^{+}$subset of DCs (46). DNGR-1 was also expressed, at a significantly lower level, by a subset of CD $11 \mathrm{~b}^{\text {lo }}$ $\mathrm{B} 220^{+}$Flt3L BMDCs, which are equivalent to pDCs (Figure 2B). We conclude that mouse DNGR-1 is highly expressed on CD $8 \alpha^{+}$ $\mathrm{cDCs}$ and to a lesser extent on a subset of $\mathrm{pDCs}$, with no expression on other cell types.

Anti-DNGR-1 selectively labels CD8 $\alpha^{+} D C s$ and pDCs in vivo. To determine whether CD $8 \alpha^{+}$DC and PDC populations can be labeled with anti-DNGR-1 antibody in vivo, we injected mice i.v. with a saturating dose (100 $\mu$ g; see below) of anti-DNGR-1 antibody conjugated to Alexa Fluor 488 or with the same amount of similarly conjugated isotype-matched control. Analysis of total spleen or lymph node cells 16 hours after injection showed specific labeling of CD8 $\alpha^{+}$DCs and pDCs, although the intensity of the signal was much greater on the former DC type $\left(\mathrm{CD} 8 \alpha^{+} \mathrm{DC} \mathrm{MFI} \approx\right.$ $350-400$ as compared with $\mathrm{pDC}$ MFI $\approx 65-70$; Figure $3 \mathrm{~A}$ and Supplemental Figure 7). No other leukocyte population was labeled by this procedure, demonstrating the remarkable in vivo specificity of anti-DNGR-1 (Figure 3A and Supplemental Figure 7). In contrast, anti-DEC-205 binds to multiple cell types when used at the same dose and, in addition to CD $8 \alpha^{+}$DCs, strongly labels CD11 ${ }^{\text {lo }}$ skin-derived DCs and stains CD11c-negative cells (Supplemental Figure 7). Notably, even local administration of small amounts of labeled anti-DNGR-1 antibody into footpads was sufficient to label spleen DC subsets (Figure 3B). Low doses of antibody (e.g., $2 \mu \mathrm{g}$ ) preferentially labeled CD $8 \alpha^{+}$DCs over pDCs, consistent with the relative expression levels of DNGR-1 in the 2 subsets and suggesting that such low levels could be used to selectively target CD8 $\alpha^{+}$DCs in vivo (Figure $3 \mathrm{~B}$ ). We conclude that anti-DNGR-1 administration can be used to specifically label $\mathrm{CD} 8 \alpha^{+} \mathrm{cDCs}$ and, to a lesser degree, $\mathrm{pDCs}$ in vivo.

DNGR-1 is an endocytic receptor. Because many C-type lectins on myeloid cells serve as endocytic receptors $(34,35)$, we tested the ability of DNGR-1 to be internalized from the cell surface. Flt3L BMDCs were labeled at $4^{\circ} \mathrm{C}$ with biotin-anti-DNGR-1, washed, and incubated at $4^{\circ} \mathrm{C}$ or $37^{\circ} \mathrm{C}$ for different lengths of time before staining with streptavidin-PE. Staining of the CD $8 \alpha^{+}$-like subset among the Flt3L BMDC population was reduced 4 -fold after 2 hours incubation at $37^{\circ} \mathrm{C}$, with minimal decrease in cells 

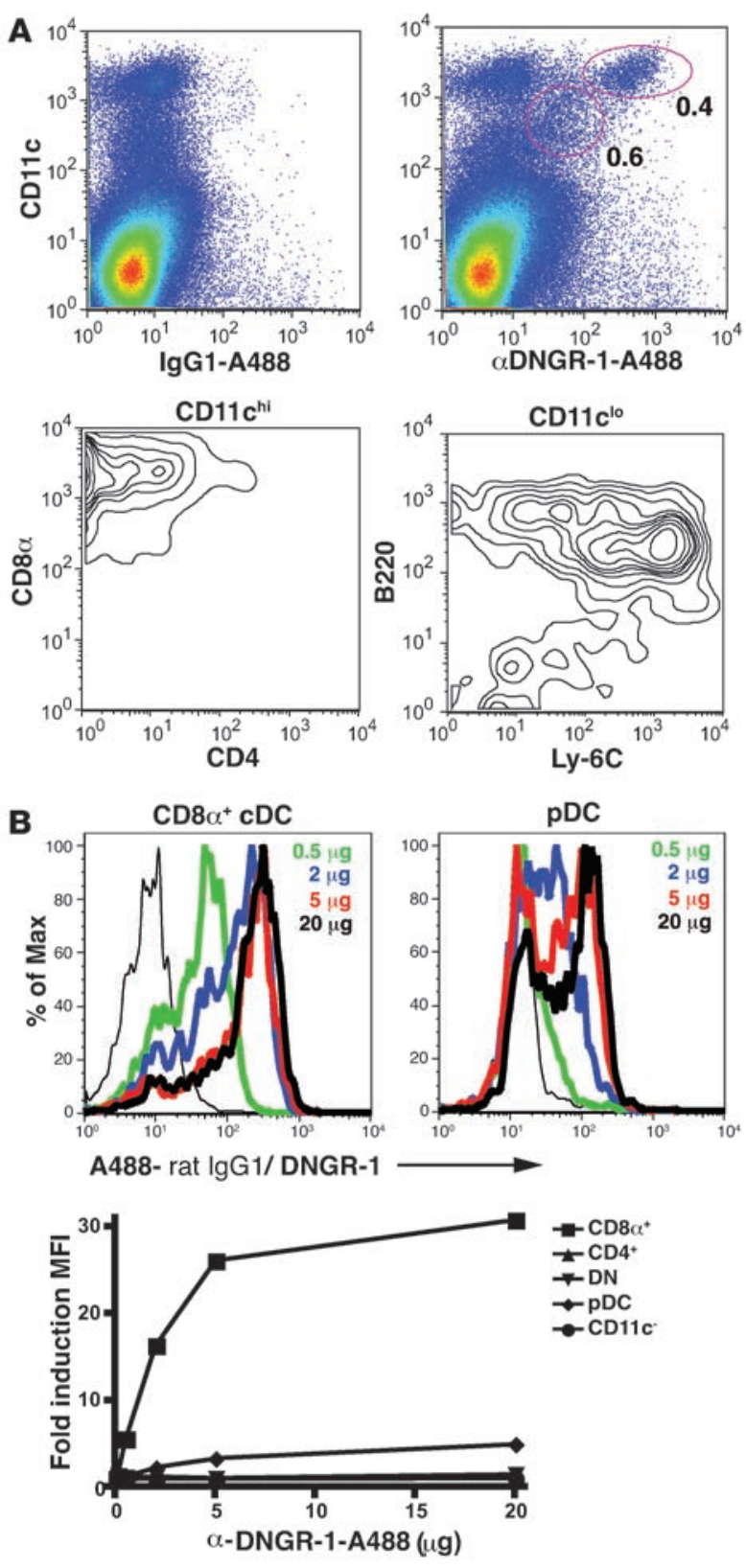

incubated at $4^{\circ} \mathrm{C}$ (Figure 4A). Confocal analysis of cells stained with anti-DNGR-1 Alexa Fluor 488 conjugates revealed the presence of $\mathrm{mAb}$ in intracellular compartments following 2 hours incubation at $37^{\circ} \mathrm{C}$ (Figure 4B). Similar data were obtained in a heterologous cell type transfected to express DNGR-1 (data not shown). Thus, DNGR-1 can mediate delivery of bound antibody to the endocytic pathway.

Anti-DNGR-1 can deliver antigen in vivo to $C D 8 \alpha^{+}$DCs for $M H C$ class I cross-presentation. To assess whether the endocytic ability of DNGR-1 and its selective expression pattern can be exploited as a means of delivering antigen for presentation to $T$ cells, we tested a model of cross-presentation. We covalently coupled anti-DNGR-1 or an isotype-matched control $\mathrm{mAb}$ to a biotinylated derivative of SIINFEKL, the immunodominant peptide in the $\mathrm{H}-2 \mathrm{~K}^{\mathrm{b}}$-restricted CTL response to OVA protein (SIINFEKLC-eahx-biotin [S1]; see

\section{Figure 3}

Specific labeling of CD8 $\alpha^{+}$DCs and pDCs in vivo with anti-DNGR-1 mAbs. (A) Mice were injected i.v. with $100 \mu \mathrm{g}$ of Alexa Fluor 488-conjugated anti-DNGR-1 (7H11) or isotype-matched control (rat IgG1), and splenocytes were analyzed 1 day later. Dot plots show CD11c versus Alexa Fluor 488 in anti-DNGR-1-injected (right panel) or rat lgG1-injected (left panel) mice. Contour plots show CD4 versus CD8 $\alpha$ and Ly6C versus B220 profiles of the CD11 $\mathrm{c}^{\text {hi }}$ and CD11 $\mathrm{c}^{\text {int }} \mathrm{DNGR}-1^{+}$ populations circled in the dot plot. Numbers represent percentage of events in the indicated gate. (B) Mice were injected s.c. with the indicated doses of Alexa Fluor 488-conjugated anti-DNGR-1 (7H11) or a single dose of isotype-matched control (rat lgG1, $20 \mu \mathrm{g} /$ mouse), and splenocytes were analyzed 1 day later. Histograms show staining of CD $8 \alpha^{+}$DCs or pDCs obtained with different doses of anti-DNGR-1 (green line, $0.5 \mu \mathrm{g}$; blue line, $2 \mu \mathrm{g}$; red line, $5 \mu \mathrm{g}$; thick black line, $20 \mu \mathrm{g}$ ) or isotype-matched control (thin black line). Lower panel shows MFI with anti-DNGR-1 divided by that obtained with $20 \mu \mathrm{g}$ of isotypematched control for each DC subset or for non-DC spleen cells.

Methods). All S1-mAb conjugates contained between 1 and 1.2 biotin molecules (i.e., 1-1.2 peptides) per antibody and could be presented by live but not by fixed DCs in vitro, indicating that they are not susceptible to extracellular proteolysis and must be processed by the cells in order to release the antigenic peptide (data not shown). Mice were injected i.v. with $2 \mu \mathrm{g}$ of either conjugate, and splenocytes were recovered 16 hours later, separated on the basis of CD11c expression, and tested for the ability to stimulate OT-I T cells as a readout for OVA peptide presentation (Figure $5 \mathrm{~A})$. Only CD $11 \mathrm{c}^{+}$splenocytes from mice that had received antiDNGR-1-S1 were able to induce OT-I proliferation and IFN- $\gamma$ production (Figure 5A), although all cell fractions were stimulatory when pulsed ex vivo with SIINFEKL peptide (data not shown). To identify the APCs involved, CD $11 \mathrm{c}^{+}$cells from mice treated with anti-DNGR-1-S1 were sorted into the 3 major subsets of cDCs. Only the CD $8 \alpha^{+}$subset of cDCs was able to stimulate OT-I cells (Figure 5B), although all subsets were equally competent to do so in the presence of added peptide (not shown; see ref. 9). Notably, pDCs purified from anti-DNGR-1-treated mice did not stimulate OT-I cells (data not shown). However, the same cells stimulated only weakly in the presence of added SIINFEKL peptide ( 60 -fold lower response than for $\mathrm{cDC}$ subsets), suggesting that they are poor APCs under these conditions. We conclude that anti-DNGR-1 mAbs can be used to selectively deliver exogenous antigen for cross-presentation by CD $8 \alpha^{+}$DCs in vivo.

Antigen targeting to DNGR-1 together with adjuvant induces CTL priming. We explored whether targeting in vivo with anti-DNGR-1 conjugated to S1 peptide could induce specific CTL priming in the presence or absence of anti-CD40, often used as an adjuvant in antibody targeting experiments $(23,24)$. Mice were injected with $2 \mu \mathrm{g}$ of anti-DNGR-1-S1 or isotype-matched control S1 \pm anti-CD40 $(25 \mu \mathrm{g})$ (Figure 6). To test for induction of CTL activity in vivo, 5 days later we infused splenocytes from congenic CD45.1 B6.SJL mice loaded with different doses of CFSE and SIINFEKL peptide and monitored the specific elimination of the peptidepulsed cells. Mice given S1 coupled to control mAbs did not eliminate target cells irrespective of anti-CD40 coadministration (Figure 6A). In contrast, target cells were completely eliminated from mice given S1 coupled to anti-DNGR-1 together with anti-CD40 (Figure 6A). No response was seen when the anti-CD40 mAb was omitted (Figure 6A). Conversely, other adjuvants such as poly I:C could substitute for anti-CD40 in promoting cross-priming to 

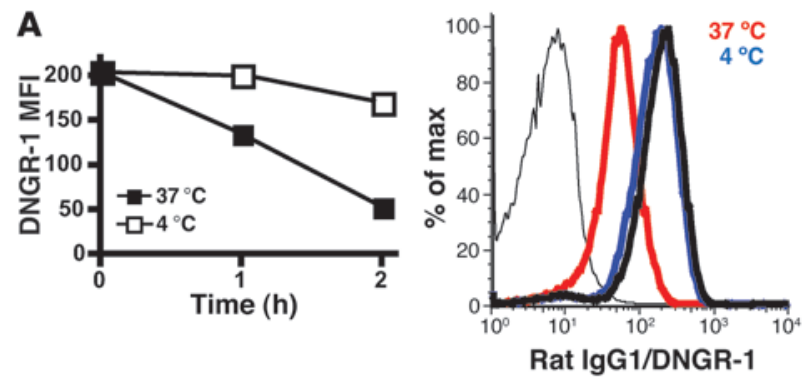

B
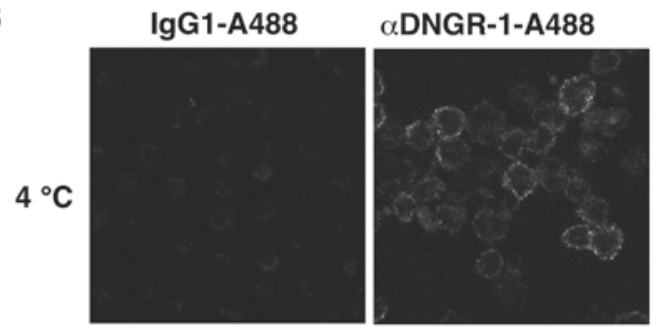

$37^{\circ} \mathrm{C}$
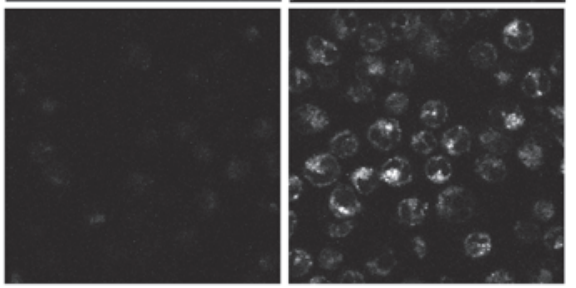

anti-DNGR-1-S1 (data not shown). Consistent with target cell elimination, significant numbers of tetramer-positive OVA/ $\mathrm{H}-2 \mathrm{~K}^{\mathrm{b}}$-specific $\mathrm{CD}^{+} \mathrm{T}$ cells were found only in the spleens and blood of mice that had received anti-DNGR-1-S1 together with anti-CD40 (Figure 6B). Restimulation of the same cells with

\section{Figure 4}

Endocytosis of anti-DNGR-1 mAbs in Flt3L BMDCs. (A) Flt3L BMDCs were labeled with anti-DNGR-1 7H11 mAbs as detailed in Methods and incubated for the indicated times at $4^{\circ} \mathrm{C}$ or $37^{\circ} \mathrm{C}$ before adding streptavidin-PE. Data represent MFI for the CD24 hi subset. Histograms show actual staining profiles: thick black line, staining with streptavidin-PE immediately after labeling with biotin-anti-DNGR-1; blue line, after 2 hours at $4^{\circ} \mathrm{C}$; red line, after 2 hours at $37^{\circ} \mathrm{C}$; thin black line, isotype-matched control. (B) Flt3L BMDCs were labeled with Alexa Fluor 488-conjugated anti-DNGR-1 mAbs (7H11, right panels) or isotype-matched control (rat IgG1, left panels) and incubated for 2 hours at $4^{\circ} \mathrm{C}$ (upper panels) or $37^{\circ} \mathrm{C}$ (lower panels) before confocal analysis. Image represents a single optical section $(<0.7 \mu \mathrm{m})$. Note punctate staining inside cells incubated at $37^{\circ} \mathrm{C}$, indicative of endocytosis. Original magnification, $\times 630$.

SIINFEKL peptide in vitro resulted in secondary expansion, with IFN- $\gamma$ production and specific killing activity (Figure 6C). Identical results were obtained using anti-DNGR-1 conjugated to a longer peptide of OVA containing the SIINFEKL epitope (S2, SIINFEKLTEWTSSNVMEERC-eahx-biotin; data not shown) or to full-length OVA protein (Figure 6D). Notably, free S1 peptide was unable to induce in vivo killing responses or elicit a significant number of tetramer-positive cells even when given at 100 times over the amount present in anti-DNGR-1-S1 conjugates (Supplemental Figure 8). We conclude that targeting of exogenous antigen to DNGR-1 together with an appropriate adjuvant allows efficient cross-priming of $\mathrm{CD}^{+} \mathrm{T}$ cells.

Antigen targeting to DNGR-1 together with adjuvant promotes tumor immunity. To determine whether DNGR-1 targeting can be used for tumor immunotherapy, we first tested a melanoma prevention model. We gave mice a single dose of anti-DNGR-1-S1 or control $\mathrm{mAb}$ conjugated to $\mathrm{S} 1(2 \mu \mathrm{g})$ together with anti-CD40 $(25 \mu \mathrm{g})$ and,
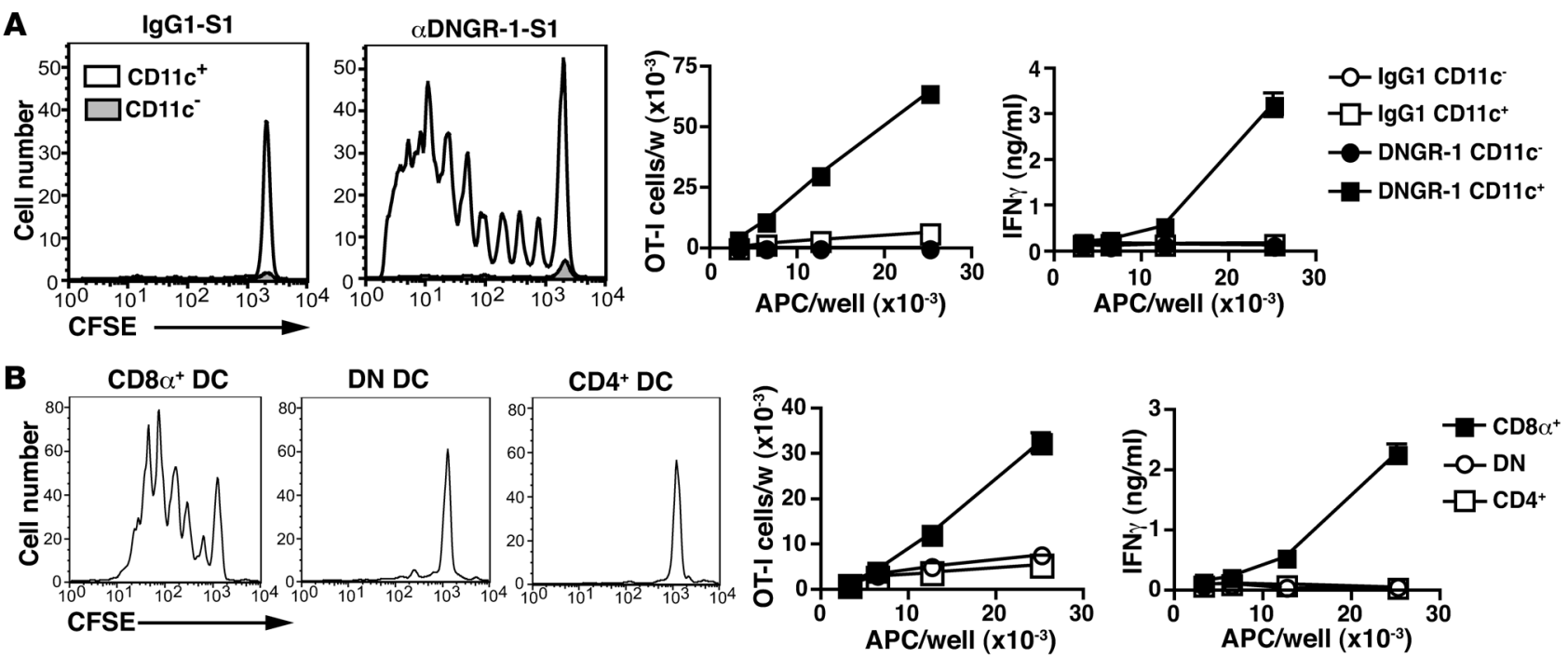

Figure 5

Antigen targeted to DNGR-1 in vivo is cross-presented by CD8 $\alpha^{+}$DCs. (A) $2 \mu g$ S1-conjugated anti-DNGR-1 (7H11) or rat IgG1 isotype-matched control mAbs were injected i.v. The next day, $C D 11 c^{+}$and $C D 11 c^{-}$spleen cell fractions were prepared, and graded numbers were cultured for 4 days with CFSE-labeled OT-I cells. Histograms show CFSE profiles of OT-I cells incubated with $25 \times 10^{3} \mathrm{CD}_{11 \mathrm{C}^{-}}$or CD11C $\mathrm{C}^{+}$splenocytes. Right panels show absolute number of OT-I cells per well and IFN- $\gamma$ content in supernatants. (B) The indicated DC subsets purified from mice injected with $2 \mu \mathrm{g}$ S1-anti-DNGR-1 (7H11) were cultured for 3 days with CFSE-labeled OT-I cells. Response was analyzed as in A. Data are representative of at least 3 experiments. 

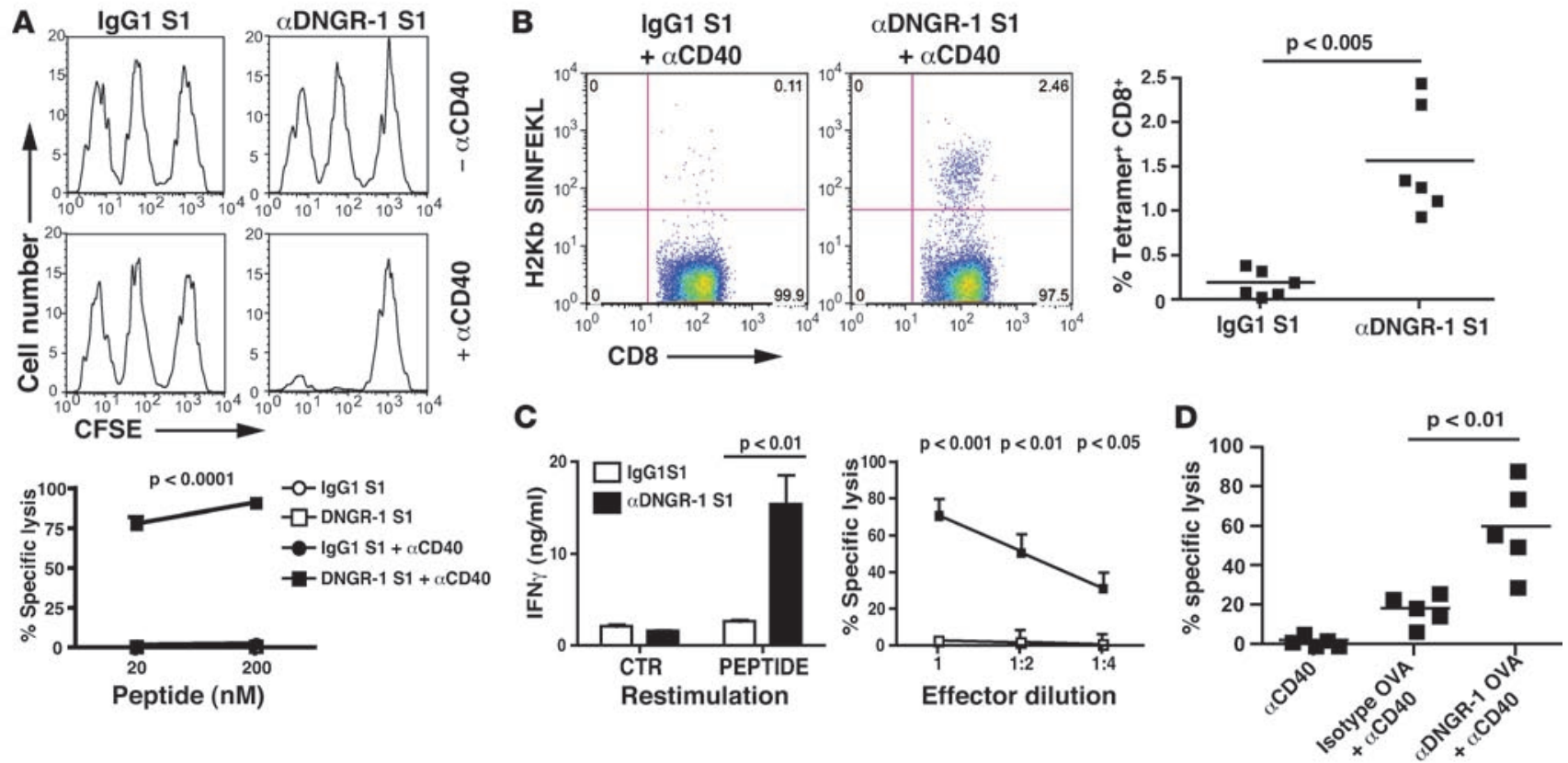

Figure 6

CTL priming with antigen targeting to DNGR-1 plus anti-CD40. $2 \mu \mathrm{g} \mathrm{S1-conjugated} \mathrm{anti-DNGR-1} \mathrm{(7H11)} \mathrm{or} \mathrm{rat} \mathrm{IgG1} \mathrm{isotype-matched} \mathrm{control}$ mAbs were injected s.c. with or without anti-CD40 $(25 \mu \mathrm{g})$ as indicated. Target cells were injected 5 days later, and mice were analyzed on day 6 . (A) In vivo CTL activity as measured by target cell elimination. Histograms show target cell frequency in representative mice from each group (CFSE ${ }^{\circ}, 20 \mathrm{nM}$ peptide; CFSE int, $200 \mathrm{nM}$ peptide; CFSEhi, no peptide). Graph shows mean \pm SEM of percentage of specific lysis in 1 experiment of 3 ( $n=6$ mice/group). All groups are shown, but the only one in which killing was detectable was that receiving anti-DNGR-1-S1 plus anti-CD40. (B) H-2K $\mathrm{K}^{\mathrm{b}}-\mathrm{SIINFEKL}$ tetramer staining of splenocytes. Left panel shows representative dot plots of tetramer staining versus CD8 in gated $\mathrm{CD}^{+}$Thy $1^{+} \mathrm{T}$ cells. Right panel shows frequency of tetramer-positive CD8 ${ }^{+} \mathrm{T}$ cells in 1 experiment of 3 ( $n=6$ mice/group). (C) In vitro restimulation with $1 \mu \mathrm{M}$ SIINFEKL (PEPTIDE) or medium alone (CTR). Left panel IFN- $\gamma$ content in supernatants at the end of the 5-day culture. Right panel shows specific CTL activity of in vitro-restimulated cells against EL4 targets loaded with $2 \mu \mathrm{M}$ of SIINFEKL. Data are the average + SEM of all cultures ( $n=6$ mice/group, restimulated individually). $P$ values were calculated using Student's $t$ test. (D) OVA protein conjugated to anti-DNGR-1 induces CTL priming in vivo. Mice were immunized s.c. in the paw with $2 \mu g$ anti-DNGR-1 or isotype control antibodies conjugated to OVA protein in the presence of $25 \mu \mathrm{g}$ of anti-CD40. In vivo killing activity was analyzed as in A using targets loaded with $200 \mathrm{nM}$ SIINFEKL peptide. Results represent individual mice and the mean for 1 representative experiment out of $3 . n=5 ; P<0.01, t$ test.

1 month later, challenged them with $2 \times 10^{5}$ B16-OVA-GFP melanoma cells i.v. (Figure 7A). The number of lung pseudometastases determined 18 days later was greatly reduced in the group pretreated with anti-DNGR-1-S1 plus anti-CD40 but not in mice treated with the control S1-mAb, indicating that DNGR-1 targeting can generate long-lasting CTL memory that protects against tumor challenge (Figure 7A). To determine whether it was also effective in a more stringent therapy setting, we delayed treatment until after tumor implantation. Mice were inoculated i.v. with B16-OVAGFP melanoma cells and 3 days later were given control mAb-S1 or anti-DNGR-1-S1 plus anti-CD40. The number of lung tumors at day 18 revealed that antigen targeting to DNGR-1 together with anti-CD40 is a highly effective therapy whereas the same amount of antigen given in untargeted form has no effect (Figure 7B). Consistent with the observed therapeutic effect, spleens from treated mice contained a high frequency of OVA/H-2 $\mathrm{K}^{\mathrm{b}}$-specific $\mathrm{CD}^{+}$ $\mathrm{T}$ cells (Figure 7C), which could be restimulated in vitro to produce IFN- $\gamma$ and kill specific targets (Figure 7D).

We extended the experiments to determine whether anti-DNGR-1 targeting can also be used to induce immune responses to endogenous melanocyte differentiation proteins that can serve as B16 tumor-associated antigens (47-49). We synthesized biotinylated peptides encompassing $\mathrm{H}-2 \mathrm{~K}^{\mathrm{b}}$ - and $\mathrm{H}-2 \mathrm{D}^{\mathrm{b}}$-restricted antigenic epitopes from melanocyte lineage-specific antigen glycoprotein 100 (gp100), tyrosinase-related protein 1 (TRP-1), and TRP-2 (47-49), coupled these covalently to anti-DNGR-1, and immunized mice with the antibody conjugates together with poly I:C and anti-CD40 as adjuvants. As shown in Figure 8, a single dose of vaccine given therapeutically 3 days after transfer of B16 melanoma cells induced nearly complete eradication of lung pseudometastases. This was accompanied by the induction of potent IFN- $\gamma$ responses against the melanoma antigens (Figure 8). In contrast, the same antigens in untargeted form (conjugated to a control isotype-matched $\mathrm{mAb}$ ) failed to induce protection or IFN- $\gamma$ responses (Figure 8). Similar results were obtained in a prophylactic model in which the vaccine was given prior to B16 challenge (Supplemental Figure 9). We conclude that priming of specific CTL via DNGR-1 targeting can be used for prophylactic or therapeutic vaccination against mouse tumors.

Human DNGR-1 is an endocytic receptor restricted to a small subset of blood DCs. To extend these findings to humans, we cloned hDNGR-1 and generated mouse mAbs against it (see Methods). One of these mAbs was selected to analyze the pattern of DNGR-1 expression among human peripheral blood mononuclear cells. Human DNGR-1 expression was absent from lymphocytes, monocytes, NK cells, and lineage-negative, HLA-DR- cells (Figure 9A). It was also not detected in monocyte-derived DCs generated by culture in 


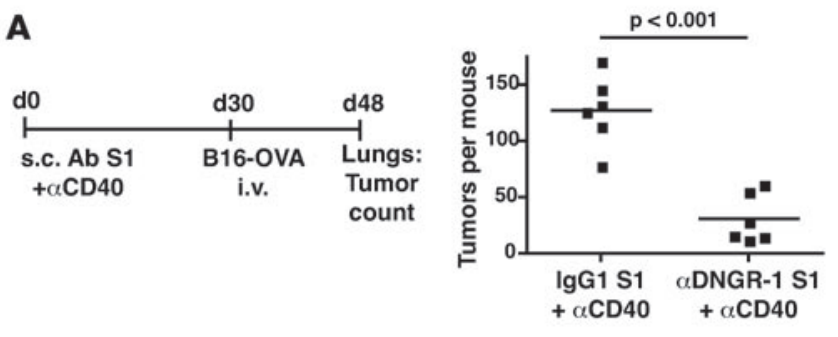

B

\begin{tabular}{|c|c|c|c|}
\hline do $\quad \mathrm{d}$ & d3 & d18 & 3 Lungs: Tumor count \\
\hline $\begin{array}{l}\text { 16-OVA s } \\
\text { i.v. }\end{array}$ & $\begin{array}{l}\text { s.c. Ab S1 } \\
+\alpha C D 40\end{array}$ & & $\begin{array}{l}\text { Spleen: Ietramer CD8 } \\
\text { Spleen: Re-stimulation }\end{array}$ \\
\hline
\end{tabular}
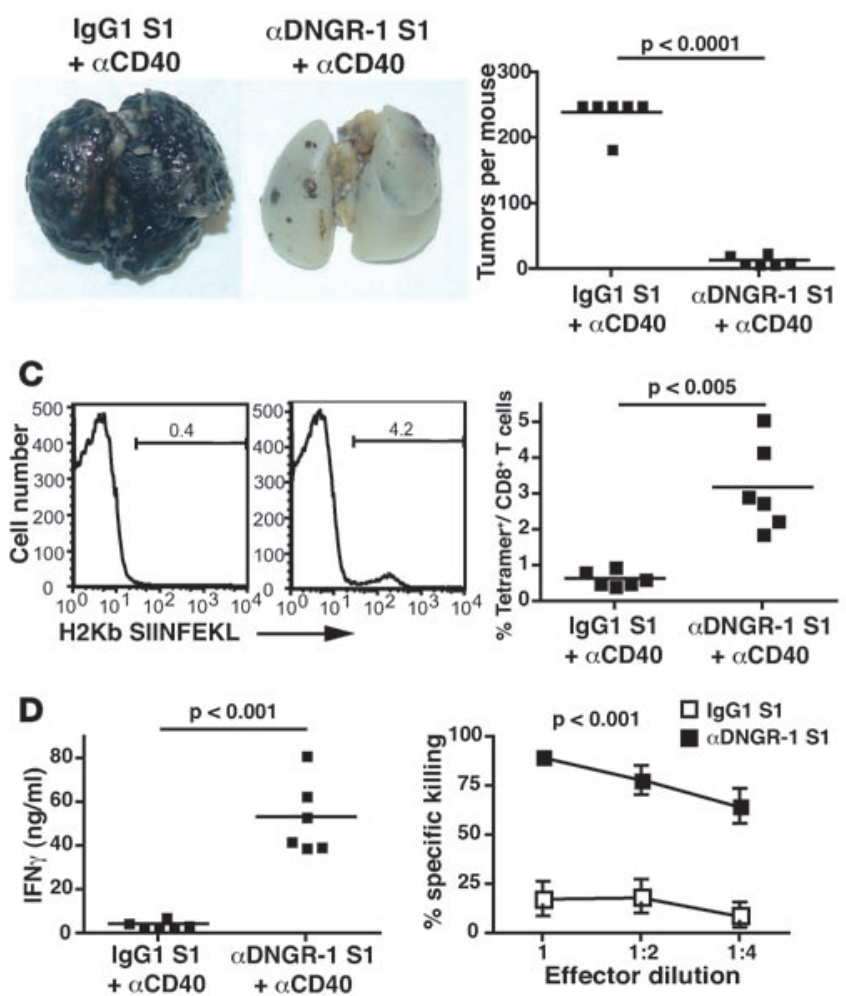

GM-CSF and IL-4 (data not shown). However, DNGR-1 expression was apparent in a discrete subpopulation of blood DCs, defined as lineage-negative, HLA-DR ${ }^{+}$cells (Figure 9A) with a characteristic dendritic morphology (Figure 10). Five distinct subsets of blood DCs have been reported, including a population of $\mathrm{CD} 123^{+} \mathrm{pDCs}$ and different subsets of putatively myeloid CD123- DCs distinguishable on the basis of expression of CD16, CD1b/c, BDCA-3, and CD34 (50). The DNGR-1 ${ }^{+}$subpopulation of DCs was negative for CD123, suggesting that human pDCs do not express DNGR-1, unlike pDCs in the mouse (Figure 9B). DNGR-1+ blood DCs were also negative for CD34, CD16, and CD1b/c. However, DNGR-1+ DCs were uniformly positive for BDCA-3 (Figure 9B). Human DNGR-1 therefore selectively marks a distinct population previously described as BDCA-3 $3^{+}$DCs.

Finally, we assessed whether human DNGR-1, like its mouse ortholog, can function as an endocytic receptor in DCs. BDCA- $3^{+}$ DCs were stained at $4^{\circ} \mathrm{C}$ with Alexa Fluor 488 -labeled antiDNGR-1. After 1 hour at $37^{\circ} \mathrm{C}$ but not at $4^{\circ} \mathrm{C}$ fluorescence was found in intracellular compartments (Figure 10). Therefore,

\section{Figure 7}

Anti-DNGR-1-S1 plus anti-CD40 is effective in prevention and therapy of OVA-expressing B16 melanoma. (A) Tumor prevention experiments were carried out as depicted. Data represent lung tumor counts in each mouse in 1 experiment out of 2 ( $n=6$ mice/group). (B) Tumor therapy experiments were carried out as depicted. Lower left panel shows representative photographs of lungs from mice treated as indicated. Right panel shows quantification of tumors in each mouse in 1 representative experiment out of 3 ( $n=6$ mice/group). (C) SIINFEKL-H2K tetramer-positive cells in spleens from mice depicted in B. Left panels show representative histograms of gated CD8+Thy $1.2^{+}$splenocytes. Right panel shows frequency of tetramer-positive CD8 ${ }^{+} \mathrm{T}$ cells in 1 representative experiment out of 3 ( $n=6$ mice/group). (D) Left panel shows splenocytes from individual mice depicted in $\mathbf{B}$ restimulated in vitro with SIINFEKL peptide $(1 \mu \mathrm{M})$. IFN- $\gamma$ levels after 5 days of culture are indicated for 1 representative experiment out of 3 ( $n=6$ mice/group). Right panel shows CTL activity after restimulation measured as in Figure $6 \mathrm{C}$. One experiment ( $n=6 \mathrm{mice} / \mathrm{group}$, restimulated individually) out of 3 is shown. Data are the average \pm SEM of all cultures. $P$ values were calculated using Student's $t$ test.

human DNGR-1 mediates endocytosis of bound antibody in BDCA $-3^{+}$DCs, thereby suggesting that it could be used for antigen targeting to these cells in humans.

\section{Discussion}

There is increasing realization that DCs constitute a heterogeneous family composed of multiple subsets with specialized functions (2). This suggests that strategies that simultaneously target multiple DC subtypes could be counterproductive, perhaps inducing competing responses. Therefore, there is clearly a need to identify markers that might serve to selectively manipulate distinct DC subtypes. Here, we report that the previously uncharacterized C-type lectin CLEC9A, here renamed DNGR-1, is a highly specific marker of a subset of mouse and human DCs and can be used to deliver exogenous antigens for MHC class I presentation in vivo, allowing efficient CTL cross-priming and tumor therapy.

Using representational difference analysis to compare mouse CD $8 \alpha^{+}$and CD $8 \alpha^{-}$DCs, we originally found that DNGR-1 transcripts were overrepresented in CD $8 \alpha^{+}$DCs. DNGR-1 encodes a type II transmembrane receptor of the C-type lectin family bearing a single extracellular CTLD and a short intracellular tail. We show that the mouse version of DNGR-1 is selectively expressed in $\mathrm{CD} 8 \alpha^{+} \mathrm{cDCs}$ and, at much lower levels, in pDCs of unstimulated animals. Notably, we report that the human version of DNGR-1 is similarly restricted in expression to a small subset of blood DCs, defined by BDCA-3 expression. These BDCA $-3^{+}$DCs have been previously described as a subtype of myeloid DCs (50-52) and share similarities with mouse CD $8 \alpha^{+}$DCs, including high levels of TLR3 mRNA, absence of TLR7 transcripts, and expression of nectin-like protein 2 (53-55). However, unlike DNGR-1, BDCA-3 is not a unique marker for this population, as it is also expressed on non-DC lineages. The highly restricted expression of DNGR-1 will therefore be useful in determining whether DNGR- $1^{+}$DCs represent the long sought-after human equivalent of mouse CD $8 \alpha^{+}$ DCs and in targeting these cells in humans.

The restricted expression and endocytic properties of DNGR-1 suggested that it might constitute a useful receptor for targeting antigens to CD $8 \alpha^{+}$DCs or to their human equivalent. Consistent with that notion, we show that antibodies against DNGR-1 specifically label CD8 $\alpha^{+}$DCs and pDCs in mice, with no detectable 
A

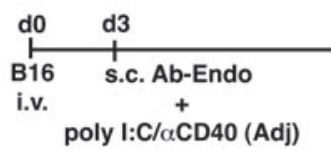

\section{IgG1-Endo + Adj}

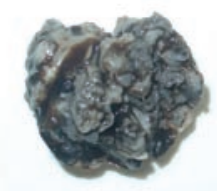

$\alpha$ DNGR-1-Endo

+ Adj

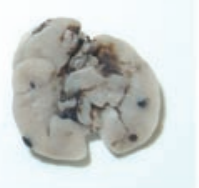

B

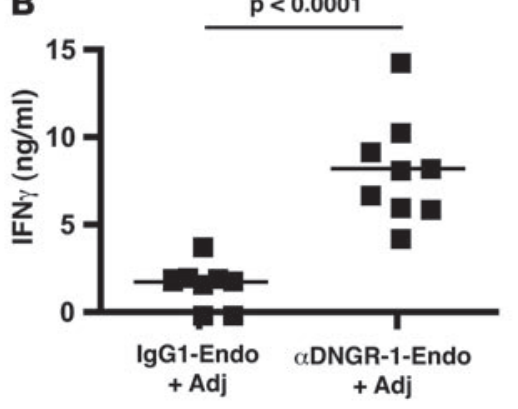

d18

Lungs: Tumor count

Spleen: Re-stimulation

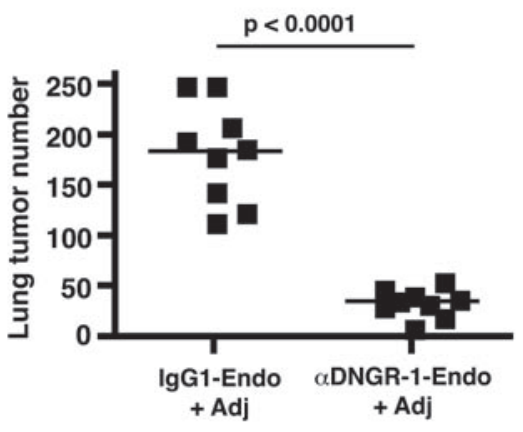

\section{Figure 8}

Immunotherapy of B16 melanoma via targeting of tumor antigens to DNGR-1. (A) Tumor therapy experiments were carried out as depicted (top panel) using peptides encompassing known epitopes of melanocyte differentiation endogenous antigens (Endo: gp100, TRP-1, and TRP-2) covalently coupled to anti-DNGR-1 or to an isotype-matched control antibody. Poly I:C plus anti-CD40 was used as adjuvant. Lower left panel shows representative photographs of lungs from mice treated as indicated. Right panel shows quantification of lung tumors in each mouse. Data are pooled from 2 independent experiments ( $n=9$ mice/group), and each point represents 1 mouse. (B) Splenocytes from individual mice depicted in A were restimulated in vitro with the melanocyte differentiation antigen peptides used for immunization $(10 \mu \mathrm{M})$. IFN- $\gamma$ levels after 2 days of culture are shown. Data are pooled from 2 independent experiments ( $n=9 \mathrm{mice} / \mathrm{group}$ ). $P$ values were calculated using the Mann-Whitney $U$ test. staining of other leukocytes. Labeling was detected in spleen even after local administration of small amounts of antibody $(2 \mu \mathrm{g})$ to footpads, illustrating the remarkable ability of the antibody to diffuse and bind specifically to distant targets. Consistent with the labeling data, in vivo delivery of a modified OVA peptide covalently coupled to anti-DNRG-1 antibody resulted in selective delivery of antigen for MHC class I cross-presentation by CD $8 \alpha^{+} \mathrm{DCs}$. The lack of presentation by $\mathrm{pDCs}$ is not unexpected considering that they express low levels of DNGR-1 and have been described as poor cross-presenting APCs (56). However, we cannot exclude that it also reflects a limitation of our assay, as freshly isolated spleen pDCs die rapidly and are poor stimulators of OT-I T cells (data not shown). Nevertheless, we believe that immune responses elicited by anti-DNGR-1 targeting in vivo primarily reflect the antigenpresenting activity of CD $8 \alpha^{+}$DCs.

The fact that DNGR-1-targeted antigen is efficiently cross-presented to $\mathrm{CD}^{+} \mathrm{T}$ cells indicates that, like the mannose receptor and DEC-205 $(24,57)$, DNGR-1 can deliver cargo to select endosomal compartments that intersect with the MHC class I processing and presentation pathway. This is consistent with the observation that anti-DNGR-1 antibody can be endocytosed by both human and mouse DCs and concentrates in intracellular vesicles, although we do not know at present the specific identity of such compartments and whether antibody internalization reflects constitutive receptor endocytosis or uptake induced by receptor cross-linking. Whether DNGR-1 targeting also promotes MHC class II presentation by CD $8 \alpha^{+}$DCs will be an interesting question for further study. Conjugates of anti-DNGR-1 to full-length OVA protein displayed a heterogenous molecular weight, which precluded determination of valency, purity, and stoichiometry (D. Sancho and C. Reis e Sousa, unpublished observations). Therefore, we only used those conjugates in a limited set of experiments in order to validate the results obtained with anti-DNGR-1 coupled to S1 or S2 peptides (e.g., Figure 6D). MHC class II presentation experiments will be facilitated by the construction of recombinant antibodies engineered to contain suitable epitopes, as pioneered by others (23).

We wished to assess the potential of DNGR-1 targeting in induction of CTL responses and tumor immunotherapy and, therefore, tested conjugates of antigen and anti-DNGR-1 mAb under the cover of anti-CD40, which provides additional signals for immunogenicity $(23,24)$. This protocol was remarkably effective at inducing specific CTL effector activity from a naive polyclonal $\mathrm{T}$ cell repertoire, as measured by multiple readouts. Thus, $2 \mu \mathrm{g}$ of anti-DNGR-1-S1, corresponding to 10-15 ng SIINFEKL peptide, plus anti-CD40 (or poly I:C) led to a large expansion of OVA $/ \mathrm{H}-2 \mathrm{~K}^{\mathrm{b}}$ tetramer-positive $\mathrm{CD}^{+} \mathrm{T}$ cells, which produced IFN- $\gamma$ and killed peptide-loaded targets in vivo or upon restimulation in vitro. In comparison, a 100-fold excess of free S1 did not induce any measurable response under the same conditions. These results are comparable to those obtained with anti-DEC-205 where small amounts of targeted antigen similarly induce potent CTL responses, as long as a DC activation stimulus is coadministered (24). To test the efficacy of this protocol in a tumor model, we chose B16 melanoma, a poorly immunogenic mouse tumor that is a notoriously difficult to treat (47-49). For this reason, we started with B16 modified to express OVA as a foreign antigen. A single administration of anti-DNGR-1-S1 plus anti-CD40 acted in a prophylactic manner to prevent B16-OVA implantation even when given 1 month before tumor challenge. The same protocol could also be used for tumor therapy, curing mice when given after B16-OVA challenge. However, to make this more relevant to cancer therapy, it was important to determine whether immunity could also be achieved against relevant tumor antigens. This was achieved by conjugating anti-DNGR-1 to peptides corresponding to melanocyte differentiation antigens that can act as B16 rejection antigens in $\mathrm{H}-2^{\mathrm{b}}$ mice (47-49). Remarkably, a single administration of such conjugates together with poly I:C plus anti-CD40 was sufficient to break tolerance to self, inducing CTL priming and B16 eradication even when 
A
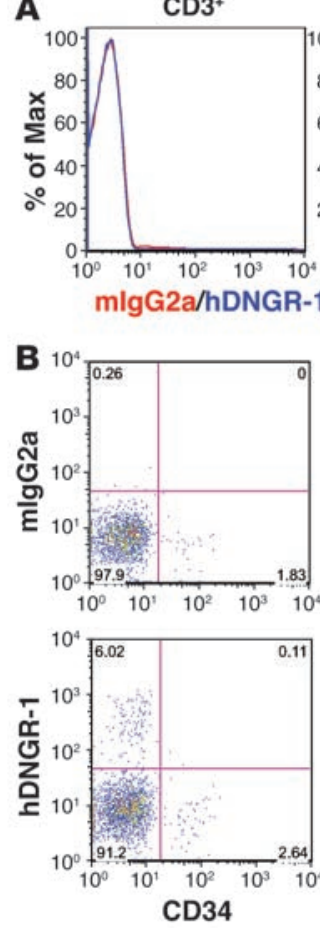

CD19+
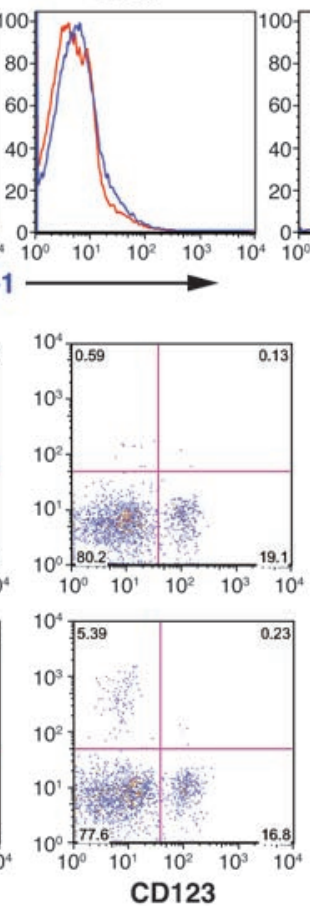

CD14 $^{+}$

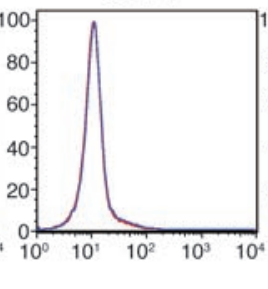

CD56 $^{+}$

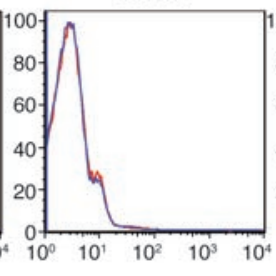

Lin' DR-

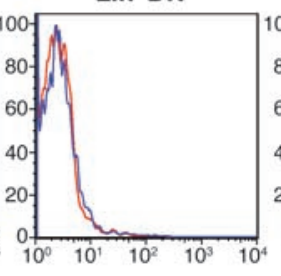

Lin $\mathrm{DR}^{+}$

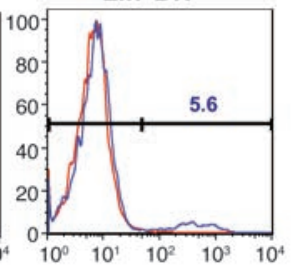

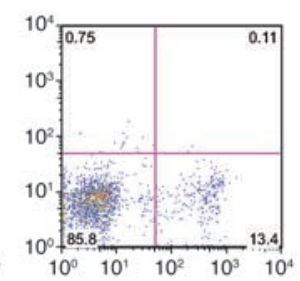
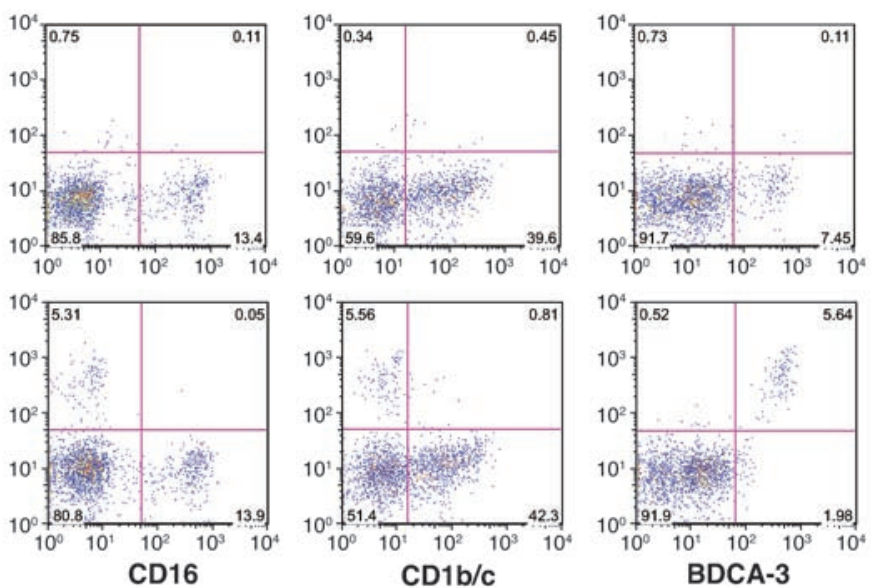

Figure 9

Human DNGR-1 expression is restricted to BDCA-3+ blood DCs. (A) Human PBMCs were stained with anti-hDNGR-1 (8F9) or an isotypematched control antibody (mouse IgG2a) and counterstained for various leukocyte markers. Histograms show DNGR-1 staining on T cells, B cells, monocytes, NK cells, lineage-negative HLA-DR- cells, and lineage-negative HLA-DR+ cells. Numbers indicate the percentage of hDNGR-1+ cells in the latter fraction. (B) PBMCs depicted in A were gated on lineage-negative HLA-DR ${ }^{+}$cells. Dot plots show staining with anti-DNGR-1 or isotype-matched control mAbs against various blood DC subset markers. Numbers represent percentage of cells in each quadrant.

given in a therapeutic mode 3 days after tumor challenge. This is a stringent test because adoptive transfer of CTLs specific for melanoma antigens is generally carried out by day 3 after i.v. inoculation of B16 cells in therapeutic experiments (49). As the generation of active CTL takes a few days, our results imply that antigen targeting via DNGR-1 together with an appropriate adjuvant is a powerful means of generating relevant antitumor immunity that could be exploited as an immunotherapeutic strategy for cancer. Whether such immunization eventually leads to autoimmunity is currently being assessed, although it is notable that vitiligo did not develop in the short time course of our tumor experiments (D. Sancho and C. Reis e Sousa, unpublished observations).

An important consideration in antigen targeting is whether the target is capable of modulating DC function. In this regard, DNGR-1 possesses a tyrosine residue in its intracellular tail within a context that resembles the hemITAM motif found in dectin-1 (35). We have recently demonstrated that dectin-1 can use this motif to couple to Syk kinase and that agonists of dectin-1 signal through Syk to promote activation of DCs $(58,59)$. However, none of the anti-DNGR-1 antibodies are able to promote DC activation in vitro or in vivo as measured by upregulation of costimulatory molecules or induction of cytokines (data not shown). In addition, anti-DNGR-1 treatment does not alter the response of DCs to heterologous stimuli such as poly I:C or CD40 ligation (data not shown). These observations suggest that anti-DNGR-1 mAbs, at least in soluble form, do not provoke signaling through the receptor. Similarly, antibodies to dectin-1 do not act as agonists for that receptor, presumably because they do not elicit the degree of crosslinking necessary to achieve productive signaling (59). Therefore, we were not surprised to find that targeting through DNGR-1 in the absence of adjuvant does not induce immunity, as reported for antigen targeting via DEC-205 (23, 24, 30-32). In fact, we do not at present have evidence that antigen targeting to DNGR-1 elicits a qualitatively different immune response from antigen targeting to DEC-205 (D. Sancho, O.P. Joffre, C. Reis e Sousa, unpublished observations). However, future studies will be needed to determine whether, like DEC-205 targeting, DNGR-1 targeting induces cross-tolerance and whether DNGR-1 may therefore constitute a promising target not only for inducing immunity but also for promoting immunological unresponsiveness.

\section{Methods}

Mice. C57BL/6, B6.SJL, and OT-I $\times \mathrm{rag}^{-1-}$ (C57BL/6 background) were bred at Cancer Research UK in specific pathogen-free conditions. All animal experiments were performed in accordance with national and institutional guidelines for animal care and were approved by the Institutional Animal Ethics Committee Review Board, Cancer Research UK.

Cells. Culture medium was RPMI 1640 (Invitrogen) supplemented with glutamine, penicillin, streptomycin, 2-mercaptoethanol (all from Invitrogen), and $10 \%$ heat-inactivated fetal calf serum (Bioclear). Mouse BMDCs were generated using GM-CSF and purified from bulk cultures by magnetic selection with anti-CD11 c microbeads (GM-CSF BMDCs). Alternatively, BMDCs were generated by culturing BM cells in the presence of $100 \mathrm{ng} / \mathrm{ml}$ of Flt3L $(\mathrm{R} \& \mathrm{D})$ for 10 days, by which time all living cells were positive for CD11c 

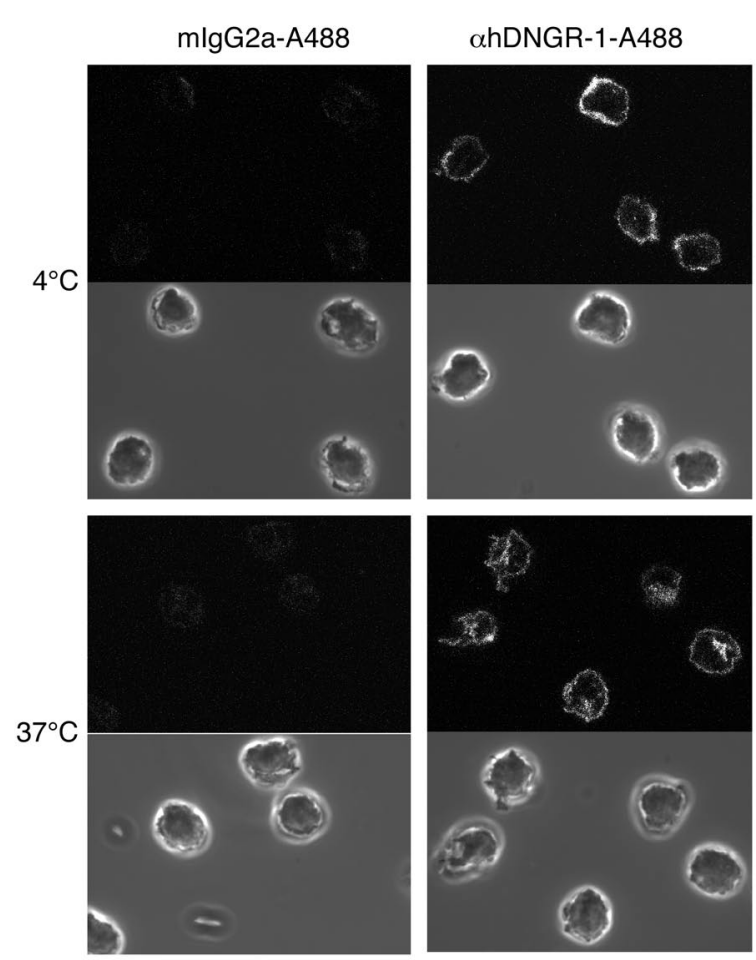

Figure 10

Endocytosis of anti-human DNGR-1 mAbs by BDCA-3+ blood DCs. Human blood BDCA-3+ DCs were stained with anti-hDNGR-1 (8F9) or an isotype-matched control antibody (mouse lgG2a), washed, and left at $4^{\circ} \mathrm{C}$ (upper panels) or $37^{\circ} \mathrm{C}$ (lower panels) for 2 hours before fixation and mounting. Representative confocal optical sections $(<0.7 \mu \mathrm{m})$ are shown. Original magnification, $\times 1260$.

(Flt3L BMDCs). Spleen cells were prepared by liberase/DNAse digestion and enriched for DCs by positive selection with anti-CD11c microbeads. OT-I $\mathrm{T}$ cells (from lymph nodes and spleen) were purified by negative selection using a cocktail of biotinylated antibodies (anti-CD11c, CD11b, B220, Fc $\gamma$ R, Gr-1, and CD4) followed by streptavidin microbeads. Human PBMCs were prepared from single-donor leukocyte buffy coats (National Blood Transfusion Service, United Kingdom) by sedimentation over Ficoll-Hypaque (GE-Healthcare). B3Z cells were a gift of N. Shastri (University of California, Berkeley, Berkeley, California, USA), and the KG-1 cell line was kindly provided by P. Cresswell (Yale University, New Haven, Connecticut, USA).

$R T-P C R$. Total RNA was extracted using Trizol (Invitrogen) from mouse subsets of DCs purified by cell sorting or from the human KG-1 cell line. cDNA was prepared by DNAse digestion (DNA-free, Ambion) and reverse transcription with Superscript II reverse transcriptase (Invitrogen), $1 \mu \mathrm{M}$ deoxyribonucletide triphosphate (dNTPs), and $10 \mu \mathrm{M}$ random hexanucleotides (Invitrogen). cDNA was amplified using 35 PCR cycles consisting of 30 seconds at $94^{\circ} \mathrm{C}, 30$ seconds at $55^{\circ} \mathrm{C}$, and 1 minute at $72^{\circ} \mathrm{C}$. Sequences of primers were as follows: mDNGR-1, forward: $5^{\prime}$-AGACTGCTTCACCACTCCAA-3'; mDNGR-1, reverse: 5'-CTTGGCACAATGGACAAGGT-3'; $\beta$-actin, forward: $5^{\prime}$-GTTTGAGACCTTCAACACCCC-3'; $\beta$-actin, reverse: 5'-GTGGCCATCTCCTGCTCGAAGTC-3'; hDNGR-1, forward: 5'-CCCAAGTCTCATTTGGAGGA-3'; hDNGR-1, reverse: 5'-AAATCTGGACGGTGTGGAAG-3'.

Generation of anti-DNGR-1 mAbs. Wistar rats or BALB/c mice were immunized 3-4 times with RBL-2H3 cells expressing respectively mouse or human DNGR-1 fused to an HA epitope. Fusion of splenocytes with the rat myeloma cell line Y3 or mouse myeloma line SP2/0 was carried out using standard procedures. For hybridoma screening, we used the B3Z cell line, which expresses a $\beta$-gal reporter for nuclear factor of activated $\mathrm{T}$ cells (NFAT) (60). This cell line was transduced with a retrovirus encoding a chimera of the extracellular domain of mouse or human DNGR-1 fused to the transmembrane region from NKRP1B and the intracellular tail of CD3 $\xi$ followed by an internal ribosome entry site (IRES) sequence and the GFP gene (61). Hybridoma supernatants were screened for the ability to bind to the DNGR-1 chimera, resulting in the activation of the NFAT reporter and induction of $\beta$-gal activity (61). Supernatants that tested positive in this assay were further screened by flow cytometry using a mixture of B3Z cells expressing the chimera DNGR-1 (GFP') and parental B3Z cells (GFP-) (see Supplemental Figure 5). This method allowed the selection of 3 rat mAbs specific for mDNGR-1 (1F6 [rat IgG1], 397 [rat IgG2a], and 7H11 [rat IgG1]) and 1 mouse mAb specific for hDNGR-1 (8F9 [IgG2a]). 7H11 anti-mDNGR-1 was selected for most of the studies described here and was conjugated to biotin or to Alexa Fluor 488 (Invitrogen) for staining or to OVA peptides for targeting, as described below.

Flow cytometry. Fluorochrome- or biotin-labeled antibodies specific for mouse CD11c, CD24, CD11b, B220, Ly6C, CD4, and CD8 $\alpha$ were from BD Biosciences - Pharmingen. Purified 2.4G2 (anti-FcyRIII/II) was from Cancer Research UK antibody production service. Mouse cell suspensions were incubated with $10 \mu \mathrm{g} / \mathrm{ml}$ of $2.4 \mathrm{G} 2 \mathrm{mAb}$ to block $\mathrm{Fc \gamma}$ receptors and were then stained in ice-cold PBS supplemented with $2 \mathrm{mM}$ EDTA, 1\% FCS, and $0.02 \%$ sodium azide. For endocytosis studies, Fc $\gamma$ R-blocked cells were labeled with $5 \mu \mathrm{g} / \mathrm{ml}$ of biotinylated anti-DNGR-1 mAb for 30 minutes at $4^{\circ} \mathrm{C}$. Cells were then washed twice and incubated for different times at $4^{\circ} \mathrm{C}$ or $37^{\circ} \mathrm{C}$ before transferring to ice and adding streptavidin PE. For in vivo labeling studies, Alexa Fluor 488-conjugated anti-DNGR-1 or isotypematched control mAbs were injected i.v. at the indicated dose, and tissues were prepared and analyzed after 16 hours. Antibodies specific for human CD3, CD14, CD19, CD56, HLA-DR, CD34, CD123, and CD16 were purchased from $\mathrm{BD}$, and $\mathrm{CD} 1 \mathrm{~b} / \mathrm{c}$ and BDCA-3 were from Abcam. Human mononuclear cells were blocked with $100 \mu \mathrm{g} / \mathrm{ml}$ human IgG (SigmaAldrich) and stained as above. Data were acquired on a FACSCalibur (BD Biosciences) and analyzed using FlowJo software (Tree Star Inc.).

Immunoprecipitation and Western blot. Phoenix cells stably expressing DNGR-1 were lysed in $50 \mathrm{mM}$ HEPES ( $\mathrm{pH} 7.4$ ), $150 \mathrm{mM}$ sodium chloride, $100 \mathrm{mM}$ sodium fluoride, $10 \mathrm{mM}$ tetrasodium pyrophosphate, $1 \mathrm{mM}$ sodium orthovanadate ( $\mathrm{pH}$ 10.0), 1 mM EDTA ( $\mathrm{pH}$ 8.0), $1.5 \mathrm{mM}$ magnesium chloride, $10 \%$ glycerol, $1 \%$ Triton X-100, 1 mM PMSF, and Complete Protease Inhibitor Cocktail Tablets (Roche). Insoluble material was discarded, and a fixed amount of lysate was subjected to immunoprecipitation using $1 \mu \mathrm{g}$ of anti-DNGR-1 or rabbit anti-HA (Santa Cruz Biotechnology Inc.) and GammaBind Plus Sepharose (GE Healthcare) beads. Proteins were eluted from beads under nonreducing conditions and separated by SDS-PAGE, transferred onto Immobilon PVDF membranes (Millipore), and probed with rabbit anti-HA or anti-Clec9a antibodies. Alternatively, cleared lysates were boiled in SDS-containing gel-loading buffer under nonreducing or reducing ( $10 \% \beta$-mercaptoethanol) conditions and separated, transferred, and probed as described above.

Microscopy. Mouse Flt3L-derived BMDCs or DNGR-1-transfected cells were incubated with $10 \mu \mathrm{g} / \mathrm{ml}$ of $2.4 \mathrm{G} 2 \mathrm{mAb}$ to block $\mathrm{F}_{\mathrm{c}} \gamma \mathrm{R}$ and were then labeled with $5 \mu \mathrm{g} / \mathrm{ml}$ of Alexa Fluor 488 -conjugated anti-DNGR-1 or rat IgG1 isotype control for 30 minutes at $4{ }^{\circ} \mathrm{C}$. For human DNGR-1+ DCs, the cells were first enriched from total PBMCs using BDCA-3 PE and anti$\mathrm{PE}$ microbeads (Miltenyi Biotec) and then sorted to purify cells with high expression of BDCA-3, which were then labeled with $10 \mu \mathrm{g} / \mathrm{ml}$ of Alexa Fluor 488-conjugated anti-human DNGR-1 or mouse IgG2a isotype control for 30 minutes at $4^{\circ} \mathrm{C}$. In both assays, mouse or human cells were 
washed twice and then incubated for 2 hours at $4^{\circ} \mathrm{C}$ or $37^{\circ} \mathrm{C}$. Cells were then allowed to adhere to poly-L-lysine-coated coverslips at room temperature, fixed in $2 \%$ paraformaldehyde, and mounted using Fluoromount (SouthernBiotech). A confocal series of differential interference contrast and fluorescence images was obtained using a laser scanning confocal microscope (Axioplan 2; Zeiss) with a $\times 63$ Plan-Apochromat NA 1.4 oil objective. Image analysis was performed with LSM 510 software (Zeiss).

Coupling of anti-DNGR-1 to antigens and antigen targeting. Peptides S1 and S2 containing the OVA 257-264 epitope (SIINFEKL) at the $\mathrm{N}$ terminus and an added cysteine and biotin at the $\mathrm{C}$ terminus were synthesized and purified by HPLC at Cancer Research UK. The same strategy was used to synthesize peptides from the melanocyte differentiation antigens, gp100 (EGSRNQDWL and KVPRNQDWL; H-2D ${ }^{\mathrm{b}}$ restricted; ref. 47), TRP-1 (TWHRYHLL and TAYRYHLL; $\mathrm{H}-2 \mathrm{~K}^{\mathrm{b}}$ restricted; ref. 48), and TRP-2 (SVYDFFVWL; H-2 $\mathrm{K}^{\mathrm{b}}$ restricted; ref. 49), each modified by the addition of cysteine-eahx-biotin at the $\mathrm{C}$ terminus. $\mathrm{mAbs}$ in PBS were treated with sulfosuccinimidyl 4-[ $\mathrm{N}$-maleimidomethyl]cyclohexane-1-carboxylate (sulfo-SMCC) for 30 minutes at room temperature to generate sulforeactive groups in tertiary amines. The activated antibody was purified by molecular size exclusion chromatography (Pierce Biotechnology), S1, S2, or melanocyte differentiation antigen peptides were added (5:1 molar ratio), and the conjugation reaction was allowed to proceed for 1 hour at $37^{\circ} \mathrm{C}$. Conjugates were purified using an GammaBind Plus Sepharose (GE Healthcare) column. The extent of biotinylation of the mAb was assessed to quantify the amount of peptides bound per molecule of antibody, using the FluoReporter kit (Invitrogen) per manufacturer's instructions. Fulllength OVA protein (Calbiochem) was conjugated to DNGR-1 or isotype control antibodies as previously described (24). PAGE analyses showed that apart from the expected species in nonreducing conditions (monovalent DNGR-1 + OVA, about $130 \mathrm{kDa}$ ), there were other species of higher and lower molecular weight, indicating that the conjugates were not homogeneous (not shown).

To analyze antigen presentation following DNGR-1 targeting in vivo, $2 \mu \mathrm{g}$ of S1- or S2-coupled mAbs were injected i.v. and splenocytes were separated into CD11c-positive and -negative fractions with anti-CD11c microbeads (Miltenyi Biotec). For further purification, CD11c-enriched fractions were labeled with appropriate mAbs and FACS sorted to obtain $\mathrm{CD} 11 \mathrm{c}^{\mathrm{int}} \mathrm{B} 220^{+}, \mathrm{CD} 11 \mathrm{c}^{\text {hi }} \mathrm{CD} 4^{+}, \mathrm{CD} 11 \mathrm{c}^{\mathrm{hi}} \mathrm{CD} 8 \alpha^{+}$, and CD11 $\mathrm{c}^{\text {hi }} \mathrm{CD} 4{ }^{-} \mathrm{CD} 8 \alpha$ subsets. Different numbers of DCs, as indicated in Figure 5, were cultured with $10^{5}$ OT-I cells labeled with $2 \mu \mathrm{M}$ CFSE (Invitrogen) in U-bottom plates. Three days later, proliferation was determined by CFSE dilution, gating on cells positive for V $\beta 5.1$ and CD8 and negative for TO-PRO 3. Samples were acquired with TrueCount beads to determine absolute numbers of cells. IFN- $\gamma$ in the supernatants was measured by ELISA.

CTL priming. To induce specific CTL responses, $\mathrm{mAb}-\mathrm{S} 1$ or free $\mathrm{S} 1$ peptide were injected s.c. in the hind paws $(1 \mu \mathrm{g} / \mathrm{paw})$ with or without endotoxin-free anti-CD40 (3/23, $12.5 \mu \mathrm{g} / \mathrm{paw}$; BD Biosciences - Pharmingen). Five days later, in vivo CTL assays were performed as described (62). In brief, splenocytes from B6.SJL mice (CD45.1+) were incubated with 20 $\mathrm{nM}, 200 \mathrm{nM}$, or $0 \mathrm{nM}$ SIINFEKL peptide and $0.03 \mu \mathrm{M}, 0.3 \mu \mathrm{M}$, or $3 \mu \mathrm{M}$, respectively, $\mathrm{CFSE}$ for 20 minutes at $37^{\circ} \mathrm{C}$. Labeled splenocytes were then injected i.v. $\left(10^{7} / \mathrm{mouse}\right)$, and the following day, mice were sacrificed, splenocytes were prepared, and the $\mathrm{CD} 45.1^{+}$population was analyzed for the presence of $\mathrm{CFSE}^{+}$cells. Specific killing was calculated using the formula $100 \times(1-$ [\% CFSE peptide/\% CFSE no peptide] $)$ as described (62). Blood and spleen cells were also labeled with SIINFEKL-H2 $\mathrm{K}^{\mathrm{b}}$ tetramer (Beckman Coulter), anti-CD8, and anti-Thy 1.2 and analyzed for the percentage of tetramer-positve cells among the $\mathrm{CD}^{+} \mathrm{T}$ cell population.

For in vitro restimulation of CTLs, $10^{6}$ splenocytes were cultured in the presence or absence of $1 \mu \mathrm{M}$ SIINFEKL for 5 days or $10 \mu \mathrm{M}$ of the mela- nocyte differentiation antigen peptides for 2 days. IFN- $\gamma$ in the supernatants was measured by ELISA. In vitro killing assays were performed using a modification of a previously described protocol (63). In brief, EL4 targets were incubated with $1 \mu \mathrm{M}$ CFSE and $2 \mu \mathrm{M}$ SIINFEKL or with $0.1 \mu \mathrm{M}$ CFSE and no SIINFEKL, washed, and used as targets. $10^{4}$ targets were mixed with different dilutions of effectors $(1,1: 2$, or 1:4) and plated in a 96-well U-bottom plate. Following incubation for 5 hours at $37^{\circ} \mathrm{C}$, TO-PRO 3 was added to exclude dead cells and samples were analyzed by flow cytometry. The mean percentage of survival in antigen-loaded targets was calculated relative to antigen-negative internal controls in each sample. Variation in the different target populations was assessed in wells without effectors, and all data were adjusted accordingly using the following formula: adjusted percentage survival $=100 \times(\%$ survival $/ \%$ survival in absence of effectors $)$. Finally, percentage of specific lysis was calculated using the following equation: percentage specific lysis $=100$ - adjusted $\%$ survival.

Tumor model. B16 melanoma cells were transduced to express an OVAGFP fusion protein and sorted for GFP expression. For tumor prevention experiments, $\mathrm{B} 6$ mice were injected in both hind footpads with a single dose of S1- or S2-coupled mAbs $(1 \mu \mathrm{g} / \mathrm{paw})$ together with anti-CD40 (12.5 $\mu \mathrm{g} /$ paw $)$. B16-OVA cells $\left(2.5 \times 10^{5} /\right.$ mouse $)$ were given i.v. 1 month later, and mice were sacrificed 18 days after tumor challenge. Tumor therapy experiments were done in an analogous fashion except that mice received B16-OVA 3 days prior to antibody treatment. Tumor therapy and prophylaxis experiments were also carried out with nontransduced parental B16 cells. These were given i.v. ( $5 \times 10^{5} /$ mouse) either 3 days before (therapy) or 1 day after (prophylaxis) immunization with anti-DNGR-1 or control antibody covalently coupled to a mixture of 5 peptides derived from gp100, TRP-1, and TRP-2 $(1 \mu \mathrm{g} / \mathrm{paw})$ together with anti-CD40 (12.5 $\mu \mathrm{g} / \mathrm{paw})$ and poly I:C $(5 \mu \mathrm{g} / \mathrm{paw})$. Tumor burden was assessed by counting lung foci. When these were too numerous to count (>250 per mouse), they are shown as 250 . CTL responses were monitored as described above.

Statistics. Statistical analysis was performed with 1-tailed Student's $t$ test for differences among groups or Mann-Whitney $U$ test when normality of data could not be inferred. $P<0.05$ was considered statistically significant. Quantitative data are expressed as means \pm SEM unless otherwise stated.

\section{Acknowledgments}

This work was funded by Cancer Research UK. We thank the FACS service, Animal Unit, Histopathology Department, Peptide Synthesis Service, and Equipment Park of the London Research Institute for technical support. We thank members of the Immunobiology Laboratory, Cancer Research UK, for advice and discussions and Mike Mitchell of the Bioinformatics \& Biostatistics Laboratory, Cancer Research UK, for help with sequence analysis. D. Sancho was supported by a European Molecular Biology Organization long-term fellowship (ALTF 336-2004) and by a Marie Curie Intra-European Fellowship within the 6th European Community Framework Programme (MEIF-CT-2005-009205). J.R. Carlyle is supported by a Career Development Award from the International Human Frontier Science Program Organization and operating grant funding from the Canadian Institutes of Health Research.

Received for publication November 26, 2007, and accepted in revised form April 16, 2008.

Address correspondence to: Caetano Reis e Sousa, Immunobiology Laboratory, Cancer Research UK, London Research Institute, Lincoln's Inn Fields Laboratories, 44 Lincoln's Inn Fields, London WC2A 3PX, United Kingdom. Phone: 44-20-7269-2832; Fax: 4420-7269-2833; E-mail: caetano@cancer.org.uk. 
1. Steinman, R. 2007. Dendritic cells: versatile controllers of the immune system. Nat. Med. 13:1155-1159

2. Villadangos, J., and Schnorrer, P. 2007. Intrinsic and cooperative antigen-presenting functions of dendritic-cell subsets in vivo. Nat. Rev. Immunol. 7:543-555.

3. Vremec, D., and Shortman, K. 1997. Dendritic cell subtypes in mouse lymphoid organs: cross-correlation of surface markers, changes with incubation, and differences among thymus, spleen, and lymph nodes. J. Immunol. 159:565-573.

4. Henri, S., et al. 2001. The dendritic cell populations of mouse lymph nodes. J. Immunol. 167:741-748.

5. den Haan, J.M., Lehar, S.M., and Bevan, M.J. 2000. CD8(+) but Not CD8(-) Dendritic cells cross-prime cytotoxic T cells in vivo. J. Exp. Med. 192:1685-1696.

6. Valdez, Y., et al. 2002. Major histocompatibility complex class II presentation of cell- associated antigen is mediated by CD8alpha+ dendritic cells in vivo. J. Exp. Med. 195:683-694.

7. Belz, G.T., et al. 2002. The CD8alpha(+) dendritic cell is responsible for inducing peripheral self-tolerance to tissue-associated antigens. J. Exp. Med. 196:1099-1104.

8. Scheinecker, C., McHugh, R., Shevach, E.M., and Germain, R.N. 2002. Constitutive presentation of a natural tissue autoantigen exclusively by dendritic cells in the draining lymph node. J. Exp. Med. 196:1079-1090.

9. Schulz, O., and Reis e Sousa, C. 2002. Cross-presentation of cell-associated antigens by CD8alpha+ dendritic cells is attributable to their ability to internalize dead cells. Immunology. 107:183-189.

10. Iyoda, T., et al. 2002. The CD8(+) Dendritic cell subset selectively endocytoses dying cells in culture and in vivo. J. Exp. Med. 195:1289-1302.

11. Schnorrer, P., et al. 2006. The dominant role of CD8+ dendritic cells in cross-presentation is not dictated by antigen capture. Proc. Natl. Acad. Sci. U. S. A. 103:10729-10734.

12. Carter, R.W., Thompson, C., Reid, D.M., Wong, S.Y., and Tough, D.F. 2006. Preferential induction of CD4+ T cell responses through in vivo targeting of antigen to dendritic cell-associated C-type lectin-1. J. Immunol. 177:2276-2284.

13. Dudziak, D., et al. 2007. Differential antigen processing by dendritic cell subsets in vivo. Science. 315:107-111.

14. Allan, R.S., et al. 2003. Epidermal viral immunity induced by CD8alpha+ dendritic cells but not by Langerhans cells. Science. 301:1925-1928.

15. Belz, G.T., et al. 2004. Cutting edge: conventional CD8alpha(+) dendritic cells are generally involved in priming CTL immunity to viruses. J. Immunol. 172:1996-2000.

16. Belz, G.T., et al. 2004. Distinct migrating and nonmigrating dendritic cell populations are involved in MHC class I-restricted antigen presentation after lung infection with virus. Proc. Natl. Acad. Sci. U. S. A. 101:8670-8675.

17. Belz, G.T., Shortman, K., Bevan, M.J., and Heath, W.R. 2005. CD8alpha+ dendritic cells selectively present MHC class I-restricted noncytolytic viral and intracellular bacterial antigens in vivo. J. Immunol. 175:196-200.

18. Allan, R.S., et al. 2006. Migratory dendritic cells transfer antigen to a lymph node-resident dendritic cell population for efficient CTL priming. Immunity. 25:153-162.

19. Wilson, N., et al. 2006. Systemic activation of dendritic cells by Toll-like receptor ligands or malaria infection impairs cross-presentation and antiviral immunity. Nat. Immunol. 7:165-172.

20. Edwards, A., et al. 2003. Relationships among murine CD11c(high) dendritic cell subsets as revealed by baseline gene expression patterns.
J. Immunol. 171:47-60.

21. Tacken, P., de Vries, I., Torensma, R., and Figdor, C. 2007. Dendritic-cell immunotherapy: from ex vivo loading to in vivo targeting. Nat. Rev. Immunol. 7:790-802.

22. Steinman, R., and Banchereau, J. 2007. Taking dendritic cells into medicine. Nature. 449:419-426.

23. Hawiger, D., et al. 2001. Dendritic cells induce peripheral T cell unresponsiveness under steady state conditions in vivo. J. Exp. Med. 194:769-779.

24. Bonifaz, L., et al. 2002. Efficient targeting of protein antigen to the dendritic cell receptor DEC-205 in the steady state leads to antigen presentation on major histocompatibility complex class I products and peripheral CD8+ T cell tolerance. J. Exp. Med. 196:1627-1638.

25. Bonifaz, L.C., et al. 2004. In vivo targeting of antigens to maturing dendritic cells via the DEC-205 receptor improves T cell vaccination. J. Exp. Med. 199:815-824

26. Mahnke, K., et al. 2005. Targeting of antigens to activated dendritic cells in vivo cures metastatic melanoma in mice. Cancer Res. 65:7007-7012.

27. Trumpfheller, C., et al. 2006. Intensified and protective $\mathrm{CD} 4+\mathrm{T}$ cell immunity in mice with antidendritic cell HIV gag fusion antibody vaccine. J. Exp. Med. 203:607-617.

28. Boscardin, S., et al. 2006. Antigen targeting to dendritic cells elicits long-lived T cell help for antibody responses. J. Exp. Med. 203:599-606.

29. Soares, H., et al. 2007. A subset of dendritic cells induces CD4+ T cells to produce IFN-gamma by an IL-12-independent but CD70-dependent mechanism in vivo. J. Exp. Med. 204:1095-1106.

30. Mahnke, K., Qian, Y., Knop, J., and Enk, A.H. 2003. Induction of $\mathrm{CD} 4+/ \mathrm{CD} 25+$ regulatory $\mathrm{T}$ cells by targeting of antigens to immature dendritic cells. Blood. 101:4862-4869.

31. Hawiger, D., Masilamani, R., Bettelli, E., Kuchroo, V., and Nussenzweig, M. 2004. Immunological unresponsiveness characterized by increased expression of CD5 on peripheral $\mathrm{T}$ cells induced by dendritic cells in vivo. Immunity. 20:695-705.

32. Kretschmer, K., et al. 2005. Inducing and expanding regulatory $T$ cell populations by foreign antigen. Nat. Immunol. 6:1219-1227.

33. Tacken, P.J., Torensma, R., and Figdor, C.G. 2006 Targeting antigens to dendritic cells in vivo. Immunobiology. 211:599-608.

34. Figdor, C., van Kooyk, Y., and Adema, G. 2002. C-type lectin receptors on dendritic cells and Langerhans cells. Nat. Rev. Immunol. 2:77-84.

35. Robinson, M., et al. 2006. Myeloid C-type lectins in innate immunity. Nat. Immunol. 7:1258-1265.

36. Carter, R., Thompson, C., Reid, D., Wong, S., and Tough, D. 2006. Induction of CD8+ T cell responses through targeting of antigen to Dectin-2. Cell. Immunol. 239:87-91.

37. Corbett, A.J., et al. 2005. Antigen delivery via two molecules on the CD8- dendritic cell subset induces humoral immunity in the absence of conventional “danger". Eur. J. Immunol. 35:2815-2825.

38. Jiang, W., et al. 1995. The receptor DEC-205 expressed by dendritic cells and thymic epithelial cells is involved in antigen processing. Nature. 375:151-155.

39. Mahnke, K., et al. 2000. The dendritic cell receptor for endocytosis, DEC-205, can recycle and enhance antigen presentation via major histocompatibility complex class II-positive lysosomal compartments. J. Cell Biol. 151:673-684.

40. Kraal, G., Breel, M., Janse, M., and Bruin, G. 1986. Langerhans' cells, veiled cells, and interdigitating cells in the mouse recognized by a monoclonal antibody. J. Exp. Med. 163:981-997.

41. Inaba, K., et al. 1995. Tissue distribution of the DEC-205 protein that is detected by the monoclonal antibody NLDC-145. I. Expression on dendritic cells and other subsets of mouse leukocytes. Cell. Immunol. 163:148-156.

42. Witmer-Pack, M.D., Swiggard, W.J., Mirza, A., Inaba, K., and Steinman, R.M. 1995. Tissue distribution of the DEC-205 protein that is detected by the monoclonal antibody NLDC-145. II. Expression in situ in lymphoid and nonlymphoid tissues. Cell. Immunol. 163:157-162.

43. Kato, M., et al. 2006. Expression of human DEC205 (CD205) multilectin receptor on leukocytes. Int. Immunol. 18:857-869.

44. Hao, L., Klein, J., and Nei, M. 2006. Heterogeneous but conserved natural killer receptor gene complexes in four major orders of mammals. Proc. Natl. Acad. Sci. U. S. A. 103:3192-3197.

45. Drickamer, K. 1999. C-type lectin-like domains. Curr. Opin. Struct. Biol. 9:585-590.

46. Naik, S.H., et al. 2005. Cutting edge: generation of splenic CD8+ and CD8- dendritic cell equivalents in Fms-like tyrosine kinase 3 ligand bone marrow cultures. J. Immunol. 174:6592-6597.

47. Overwijk, W.W., et al. 1998. gp100/pmel 17 is a murine tumor rejection antigen: induction of "self"reactive, tumoricidal $\mathrm{T}$ cells using high-affinity, altered peptide ligand. J. Exp. Med. 188:277-286.

48. Dyall, R., et al. 1998. Heteroclitic immunization induces tumor immunity. J. Exp. Med. 188: $1553-1561$.

49. Bloom, M.B., et al. 1997. Identification of tyrosinase-related protein 2 as a tumor rejection antigen for the B16 melanoma. J. Exp. Med. 185:453-459.

50. MacDonald, K.P., et al. 2002. Characterization of human blood dendritic cell subsets. Blood. 100:4512-4520.

51. Dzionek, A., et al. 2000. BDCA-2, BDCA-3, and BDCA-4: three markers for distinct subsets of dendritic cells in human peripheral blood. J. Immunol. 165:6037-6046.

52. Narbutt, J., et al. 2004. The distribution of peripheral blood dendritic cells assayed by a new panel of anti-BDCA monoclonal antibodies in healthy representatives of the polish population. Cell. Mol. Biol. Lett. 9:497-509.

53. Galibert, L., et al. 2005. Nectin-like protein 2 defines a subset of T-cell zone dendritic cells and is a ligand for class-I-restricted T-cell-associated molecule. J. Biol. Chem. 280:21955-21964.

54. Lindstedt, M., Lundberg, K., and Borrebaeck, C. 2005. Gene family clustering identifies functionally associated subsets of human in vivo blood and tonsillar dendritic cells. J. Immunol. 175:4839-4846.

55. Robbins, S.H., et al. 2008. Novel insights into the relationships between dendritic cell subsets in human and mouse revealed by genome-wide expression profiling. Genome Biol. 9:R17.

56. Salio, M., Palmowski, M.J., Atzberger, A., Hermans, I.F., and Cerundolo, V. 2004. CpG-matured murine plasmacytoid dendritic cells are capable of in vivo priming of functional CD8 $\mathrm{T}$ cell responses to endogenous but not exogenous antigens. J. Exp. Med. 199:567-579.

57. Burgdorf, S., Kautz, A., Böhnert, V., Knolle, P., and Kurts, C. 2007. Distinct pathways of antigen uptake and intracellular routing in CD4 and CD8 $\mathrm{T}$ cell activation. Science. 316:612-616.

58. Rogers, N.C., et al. 2005. Syk-dependent cytokine induction by Dectin-1 reveals a novel pattern recognition pathway for $\mathrm{C}$ type lectins. Immunity. 22:507-517.

59. Leibundgut-Landmann, S., et al. 2007. Syk- and CARD9-dependent coupling of innate immunity to the induction of $\mathrm{T}$ helper cells that produce interleukin 17. Nat. Immunol. 8:630-638.

60. Karttunen, J., Sanderson, S., and Shastri, N. 1992. Detection of rare antigen-presenting cells by the lacZ T-cell activation assay suggests an expression cloning strategy for T-cell antigens. Proc. Natl. Acad. Sci. U. S. A. 89:6020-6024. 
61. Mesci, A., and Carlyle, J. 2007. A rapid and efficient method for the generation and screening of monoclonal antibodies specific for cell surface antigens. J. Immunol. Methods. 323:78-87.
62. Schulz, O., et al. 2005. Toll-like receptor 3 promotes cross-priming to virus-infected cells. Nature. 433:887-892.

63. Hermans, I.F., et al. 2004. The VITAL assay: a ver- satile fluorometric technique for assessing CTLand NKT-mediated cytotoxicity against multiple targets in vitro and in vivo. J. Immunol. Methods. 285:25-40. 